\title{
FARMERS MARKET CONSORTIUM RESOURCE GUIDE
}

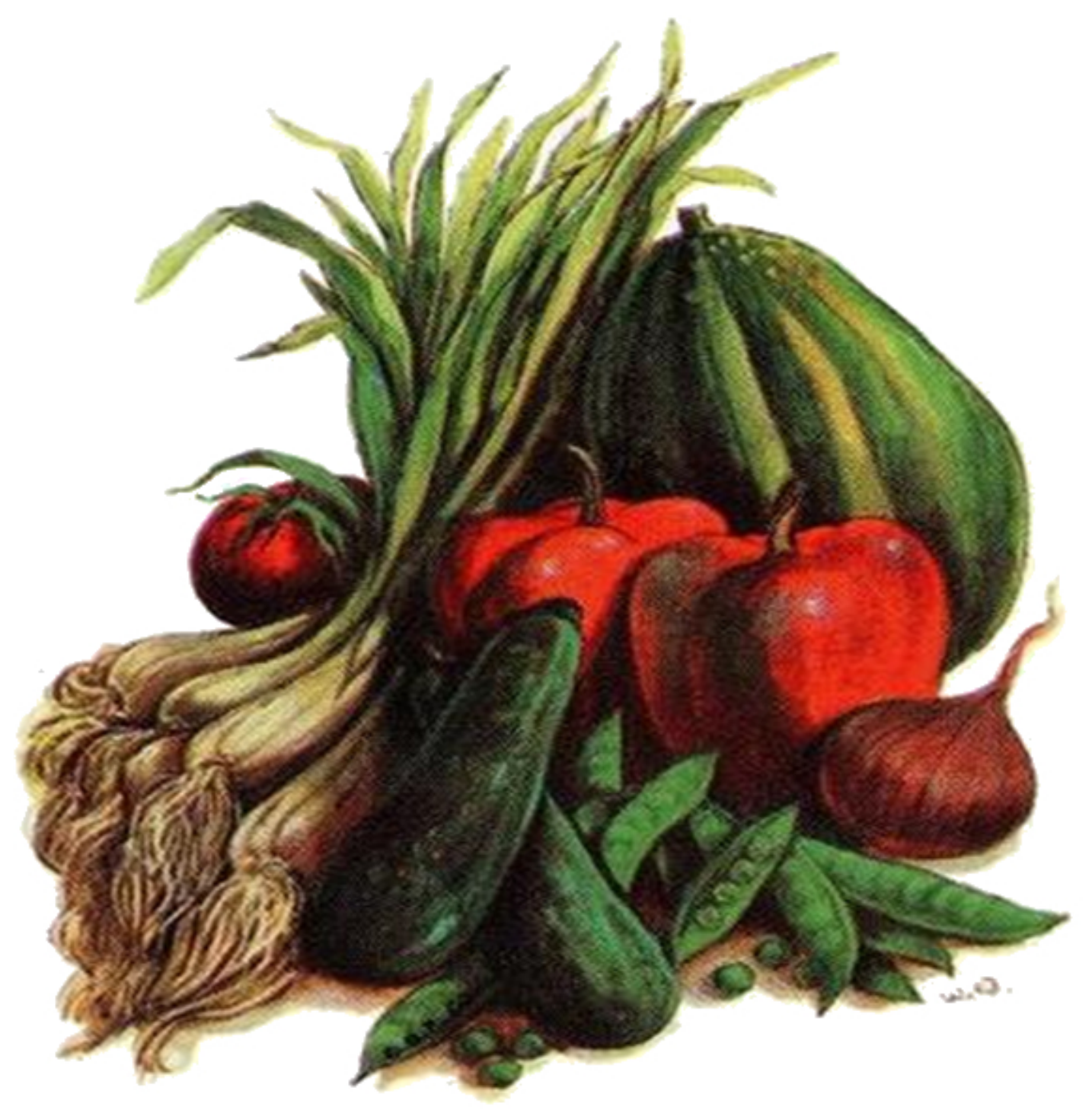

U.S. Department of Agriculture Agricultural Marketing Service

Updated November 2007 
The U.S. Department of Agriculture (USDA) prohibits discrimination in all its programs and activities on the basis of race, color, national origin, age, disability, and where applicable, sex, marital status, familial status, parental status, religion, sexual orientation, genetic information, political beliefs, reprisal, or because all or a part of an individual's income is derived from any public assistance program. (Not all prohibited bases apply to all programs.) Persons with disabilities who require alternative means for communication of program information (Braille, large print, audiotape, etc.) should contact USDA's TARGET Center at (202) 720-2600 (voice and TDD). To file a complaint of discrimination write to USDA, Director, Office of Civil Rights, 1400 Independence Avenue, S.W., Washington, D.C. 20250-9410 or call (800) 795-3272 (voice) or (202) 720-6382 (TDD). USDA is an equal opportunity provider and employer. 


\section{Farmers Market Resource Guide U.S. Department of Agriculture Updated November 2007}

1. Summary

2. Project Types

3. Overview of Federal Farmers Market Programs

4. Overview of Private Sector and Foundation Farmers Market Programs

5. Federal Farmers Market Projects

6. Private Sector and Foundation Farmers Market Projects

\section{Summary}

The latest U.S. agricultural census identifies the emergence of two trends in the farming sectora consolidation of medium and large farms and an expansion in the number of small farms. In our era of large farms, where food can travel over a thousand miles from farm to table, consumers are looking for alternative sources of food by supporting small local farmers.

Today's farmers are taking advantage of the swelling demand for locally-grown food by adopting a broad range of alternative production and marketing methods to capture this expanding market. Meanwhile, consumers are increasingly interested in knowing how their produce is grownwhether it is traditional or organic-and where it comes from. The convergence of these trends has generated a renewed interest in farmers markets across the nation.

The United States Department of Agriculture, through the Agricultural Marketing Service (AMS), is committed to the long-term support of farmers-particularly small and medium-sized farmers. Currently over 3,700 farmers markets operate in the U.S., in all fifty States and requiring many different kinds of assistance.

A Farmers Market Consortium was formed in November 2005 to further the cause of farmers markets. In addition to these USDA agencies-Cooperative State Research, Education and Extension Service, (CSREES), Food and Nutrition Service (FNS), National Resource Conservation Service (NRCS), Risk Management Agency (RMA), Rural Development (RD)_consortium participants include the U.S. Department of Health and Human Services (HHS) and the private sector, such as the Project for Public Spaces (PPS), the Kellogg and Ford Foundations, Drake University, and Winrock's Wallace Center. One recommendation from the Consortium was to create the Farmers Market Resource Guide.

The Resource Guide promotes a free flow of information between the programs that support farmers markets. It is divided into four types of projects: market development, producer training and support, consumer education and access, and market promotion.

The Resource Guide describes each of these four types, followed by an overview of the participating programs and a list of the most recent projects that support farmers markets.

(Back to table of contents) 


\section{Project Types}

Projects are divided into four types: Market Development, Producer Training and Support, Consumer Education and Access, and Market Promotion. These four types characterize the assistance needed by farmers markets.

\section{Market Development}

Market development projects help markets to expand their facilities, enhance their buildings, increase sales, conduct feasibility studies, and recruit and train market managers and vendors. Types of market development projects include:

- Site development

- Facility design

- $\quad$ Logistics within the market (loading and unloading, parking)

- Transportation (ingress and egress to and from the market)

\section{Producer Training and Support}

Producer training and support projects train producers in areas like public safety, business management, technical assistance, and direct marketing. Training workshops for different types of vendors take place at conferences and trade shows throughout the country.

Types of producer training and support projects:

- Education and training

o Conferences

o Publications

o Directories

- Management Assistance

o Regulatory requirements

o Organizational competency

- Public safety

\section{Consumer Education and Access}

Consumer education and access projects inform the consumer about services available at farmers markets. These services can vary from the promotion of healthy eating habits to alternative payment options to cooking classes. Many of these projects are initiated by surveying market customers.

Types of consumer education and access projects include:

- Surveys

- Nutrition

o Conventional

o Organic

o Processed products

- Special Supplemental Nutrition Program for Women, Infants and Children (WIC) and the Senior Farmers Market Nutrition Program (SFMNP)

- Electronic Benefits Transfer

- Public safety 


\section{Market Promotion}

Market promotion engages the community in farmers market activities, attracting more people to local markets. An effective advertising and promotion campaign helps market managers tell their community where they are and what types of activities are available at their market. In order to mount an effective campaign, market managers need to understand their customers. Market promotion programs benefit from projects that study their customers, like:

- Customer segmentation studies

- $\quad$ Distance drive-time studies

- Geographic evaluation modeling

\section{(Back to table of contents)}




\section{Overview of Federal Farmers Market Programs}

Due to the increasing number of farmers markets in the U.S. today, several Federal and private programs address the needs of farmers and community development. This section describes some Federal and private farmers market programs, each of which sponsors several projects, with contact information for each program.

\section{USDA - Agricultural Marketing Service (AMS) \\ Transportation and Marketing Programs/Marketing Services Branch (TM/MSB) (View Projects)}

\section{Program Overview}

The function of Marketing Services (MSB) is to help U.S. agricultural producers take advantage of marketing opportunities, improve farm income, and facilitate the distribution of U.S. farm products in domestic markets. MSB provides research information, technical support, training, and assistance with facility design to producers, distributors, and marketers of agricultural products. MSB helps those involved in agricultural marketing ventures to develop effective business strategies.

\section{Contact Information}

Errol Bragg, Associate Deputy Administrator

USDA/AMS/TM/MSB

1400 Independence Ave., SW

Rm. 2646-S

Mail Stop 0269

Washington, D.C. 20250

Phone: (202) 720-8317

E-mail: Errol.Bragg@usda.gov

\section{Websites}

www.ams.usda.gov/tmd/MSB/index.htm

www.ams.usda.gov/farmersmarkets/

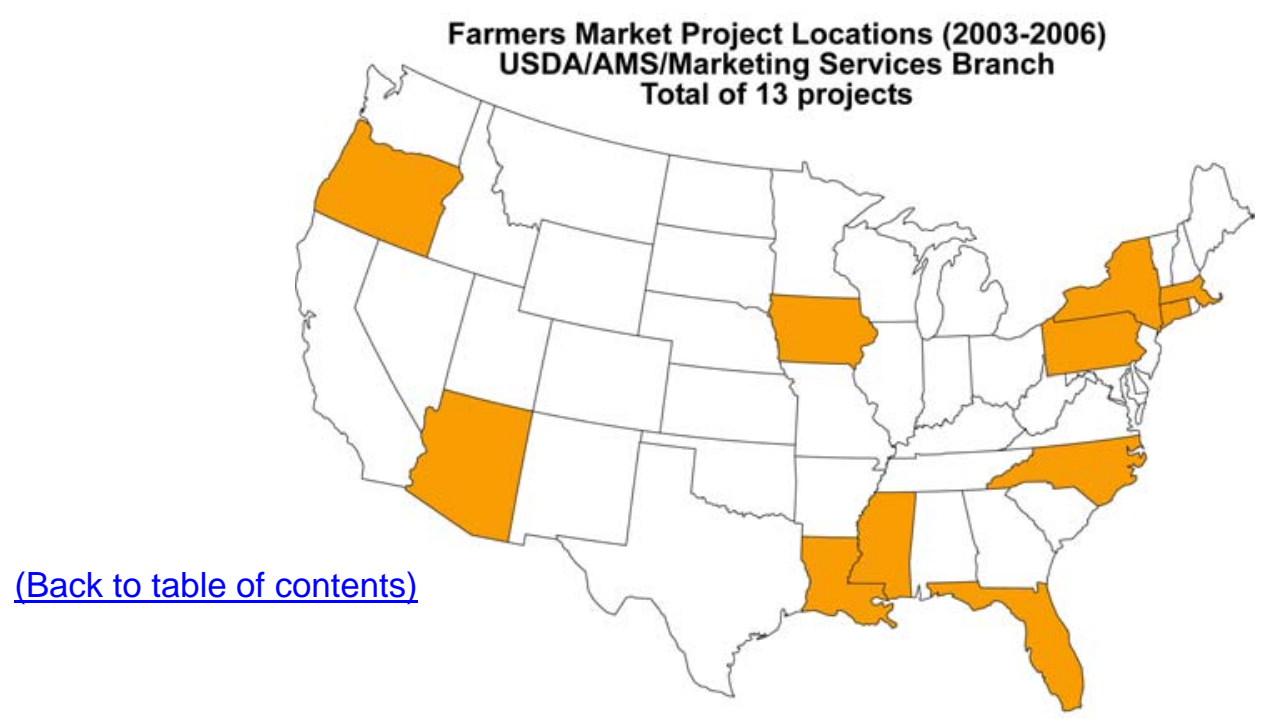




\section{USDA - Agricultural Marketing Service (AMS) \\ Transportation and Marketing Programs/Marketing Services Branch (TM/MSB) \\ Farmers Market Promotion Program (FMPP) \\ (View Projects)}

\section{Program Overview}

The Farmers Market Promotion Program (FMPP) provides grants to help eligible entities improve and expand domestic farmers markets, roadside stands, community-supported agriculture programs, and other direct producer-to-consumer market opportunities. Eligible entities under the FMPP program include agricultural cooperatives, local governments, nonprofit corporations, public benefit corporations, economic development corporations, regional farmers market authorities, and Tribal governments. In FY-2006, approximately \$1 million was allocated for the program with a maximum amount awarded for any one proposal not to exceed $\$ 75,000$.

\section{Contact Information}

Carmen H. Humphrey, Team Leader

USDA/AMS/TM/MSB

1400 Independence Ave., SW

Rm. 2646-S

Mail Stop 0269

Washington, D.C. 20250

Phone: (202) 720-8317

E-mail: Carmen.Humphrey@usda.gov

\section{Websites}

www.ams.usda.gov/tmd/MSB/index.htm

www.ams.usda.gov/farmersmarkets/

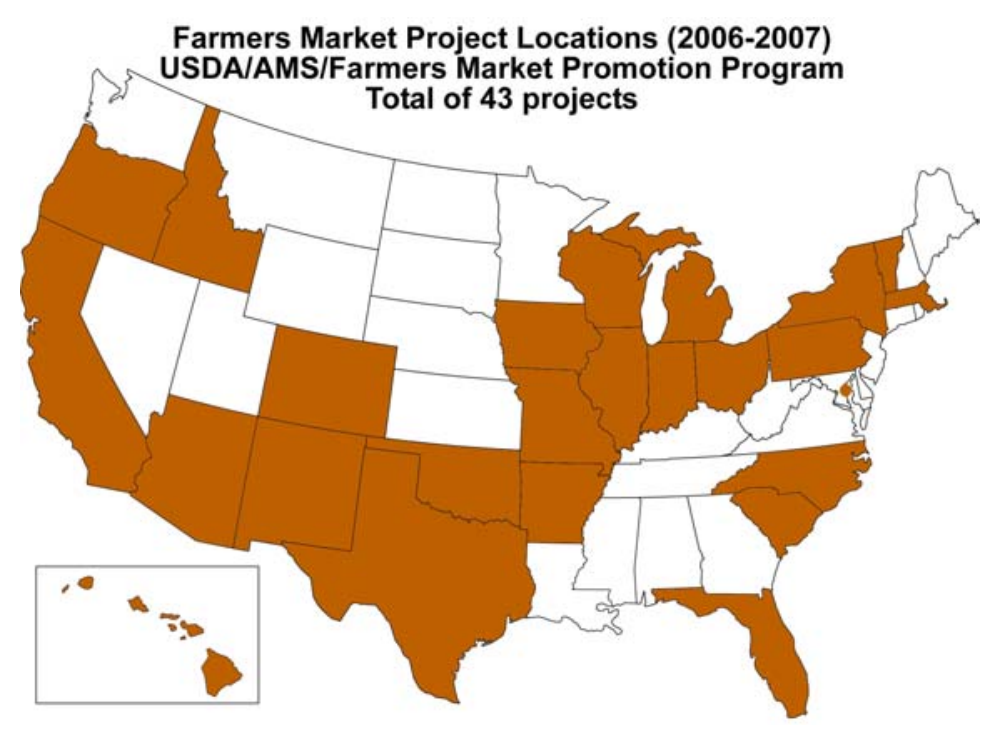

(Back to table of contents) 


\section{USDA - Agricultural Marketing Service (AMS) \\ Federal State Marketing Improvement Program (FSMIP) (View Projects)}

\section{Program Overview}

The Federal-State Marketing Improvement Program (FSMIP) provides matching funds to State Departments of Agriculture, State Agricultural Experiment Stations and other appropriate State agencies for applied research projects that address barriers, challenges, and opportunities in marketing, transportation, and distribution of U.S. food and agricultural products domestically and internationally.

Proposals that address issues of importance at the State, regional or national level are appropriate for FSMIP. FSMIP also seeks unique proposals on a smaller scale that may serve as pilot projects or case studies useful as a model for others. Proposals may involve small-, medium- or large- scale agricultural entities but should potentially benefit multiple producers or agribusinesses. Proprietary proposals that benefit one business or individual will not be considered. The program is not specifically targeted to farmers markets, although such projects have been funded.

\section{Contact Information}

Janise Zygmont, Staff Officer

USDA, AMS, FSMIP

1400 Independence Ave., SW

Rm. 4009-S

Washington, D.C. 20250

Phone: (202) 720-2704 or (202) 720-8043

E-mail: FSMIP@usda.gov or Janise.Zygmont@usda.gov

\section{Website}

www.ams.usda.gov/tmd/fsmip.htm

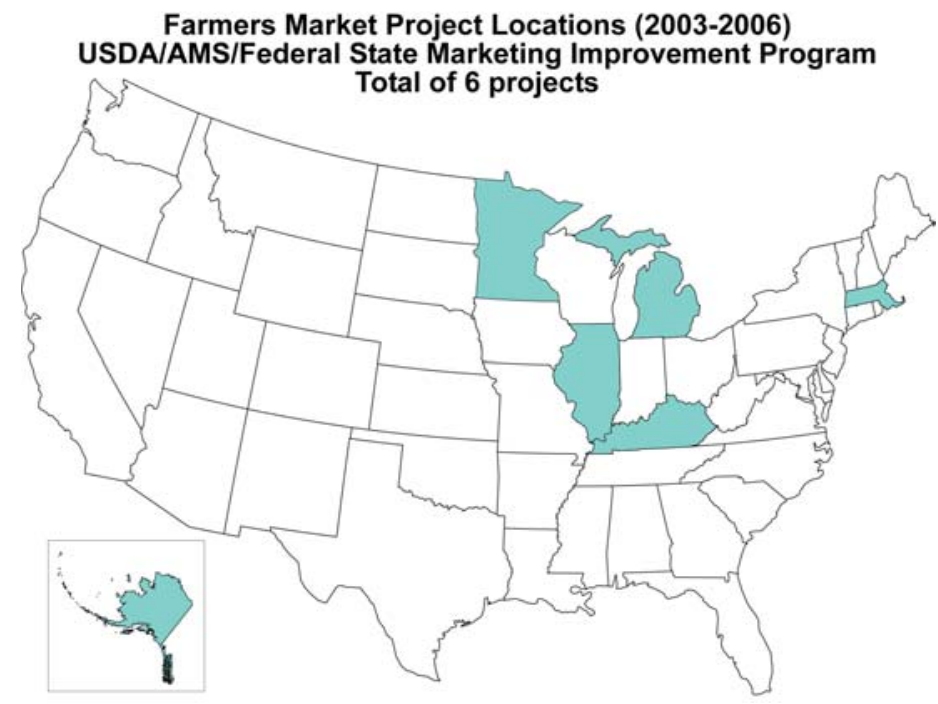

(Back to table of contents) 


\section{USDA - Cooperative State Research, Education, and Extension Service (CSREES) Community Food Project (View Projects)}

\section{Program Overview}

CSREES supports community food projects that meet the food needs of low-income people, that increase the self-reliance of communities in providing for their own needs, and that promote responses to local food, farm, and nutrition problems. It also supports efforts to develop State, local, or neighborhood food and agriculture infrastructure, plan for long-term solutions, and create innovative marketing activities that benefit agricultural producers and low-income consumers.

The program also seeks to develop linkages among sectors of the food system-including the for-profit and nonprofit sectors-to support the development of entrepreneurial projects, and to encourage long-term planning and multi-system, inter-agency collaboration.

Matching non-Federal support of the project, dollar for dollar, is required during the term of the grant. The non-Federal share may be provided through payment in cash or in-kind contributions in the form of facilities, equipment, or services. The non-Federal share may be derived from State or local governments, or from private sources.

\section{Contact Information}

Dr. Elizabeth Tuckermanty, Program Director

National Program Office

2340 Waterfront Center

USDA-CSREES, Stop 2241

Washington, D.C. 20250-2241

Phone: (202) 205-0241

E-mail: etuckermanty@csrees.usda.gov

\section{Website}

www.csrees.usda.gov/fo/funding.cfm

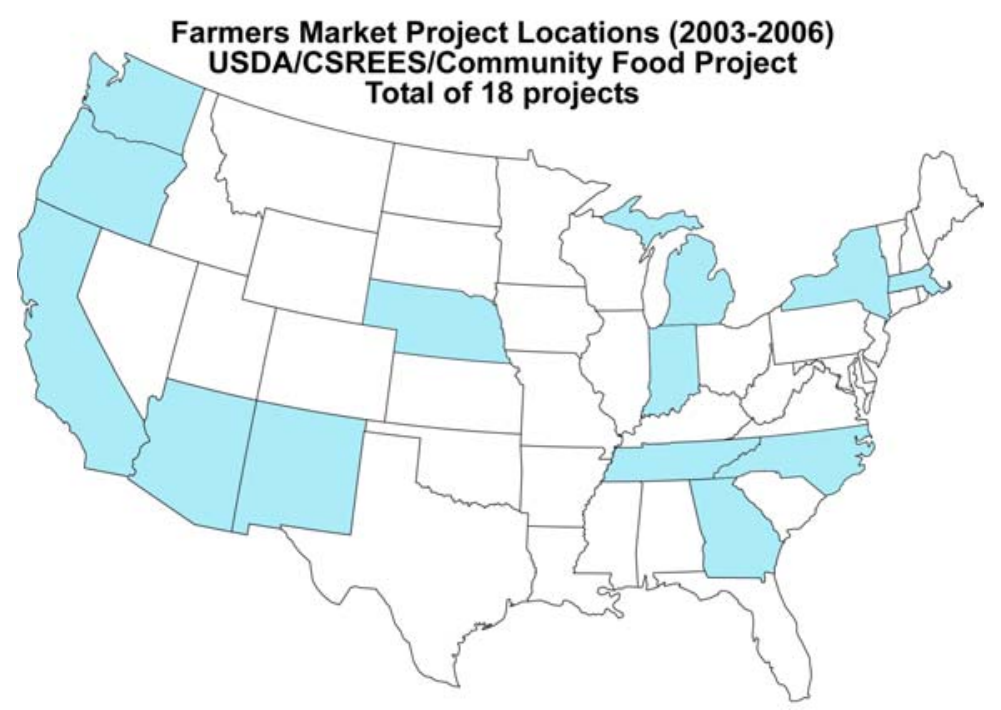

(Back to table of contents) 


\section{USDA - Cooperative State Research, Education, and Extension Service (CSREES) Sustainable Agriculture Research and Education (SARE) (View Projects)}

\section{Program Overview}

The Sustainable Agriculture Research and Education (SARE) program provides grants to advance farming systems that are profitable, environmentally sound, and beneficial to their communities. Specifically, the program awards grants to farms, universities, nonprofit organizations, and research/education institutions to improve the economic, environmental, and social sustainability of farming and ranching.

SARE also conducts educational and extension programs in an effort to increase knowledge about-and help farmers and ranchers adopt-sustainable farming practices. SARE's four regional offices administer three primary grant programs, although some offer other opportunities for community innovation, and for graduate students and agricultural professionals conducting onfarm research.

\section{Contact Information}

National Program Office

Director, Sustainable Agriculture Programs

1400 Independence Ave., SW

USDA Mail Stop 2223

Washington, D.C. 20250-2223

Phone: (202) 720-6527

Fax: (202) 720-6071

E-mail: ehauhn@csrees.usda.gov

\section{Website}

www.sare.org

Farmers Market Project Locations (2005)

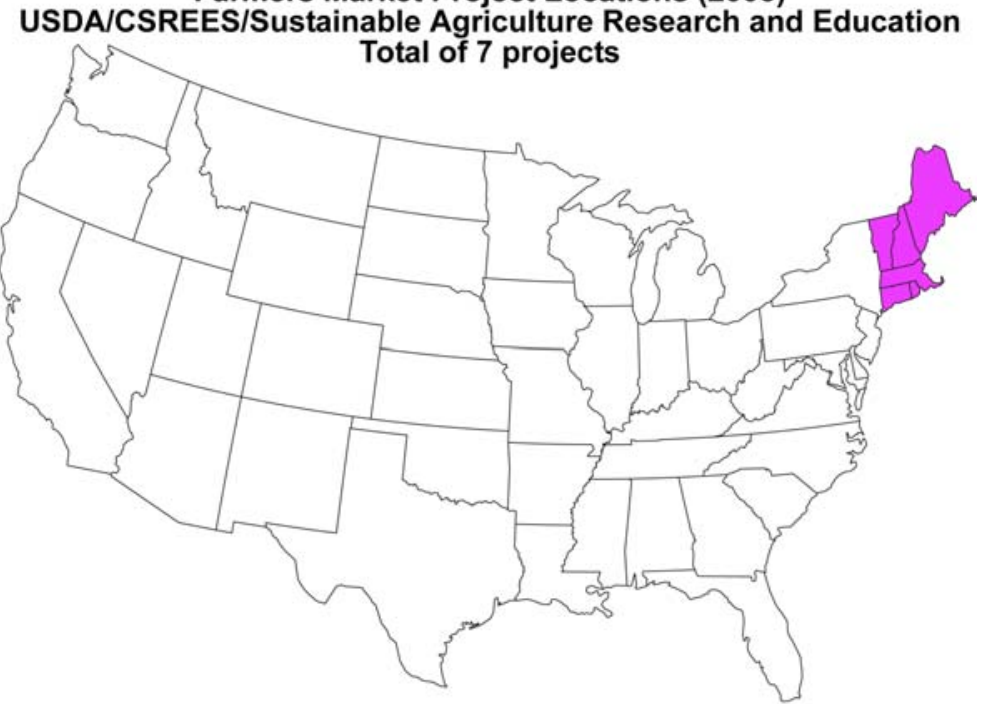

(Back to table of contents) 


\section{USDA - Food and Nutrition Service (FNS) Food Stamp Program (FSP) \\ (View Projects)}

\section{Program Overview}

The Food Stamp Program serves as the first line of defense against hunger. It enables lowincome families to buy nutritious food with coupons and Electronic Benefits Transfer (EBT) cards. Recent program changes allow food stamp recipients to use their coupons or EBT cards to buy locally grown fresh fruits and vegetables at farmers markets. FSP also helps farmers market vendors increase their sales and profits.

The FSP is the cornerstone of the Federal food assistance programs, and provides crucial support to needy households and to those making the transition from welfare to work.

\section{Contact Information}

David Barnhart

USDA/FNS/EBT Branch

3101 Park Center Dr., Rm. 403

Alexandria, VA 22302

Phone: (703) 305-2402

E-mail: David.Barnhart@fns.usda.gov

\section{Website}

www.fns.usda.gov/fsp

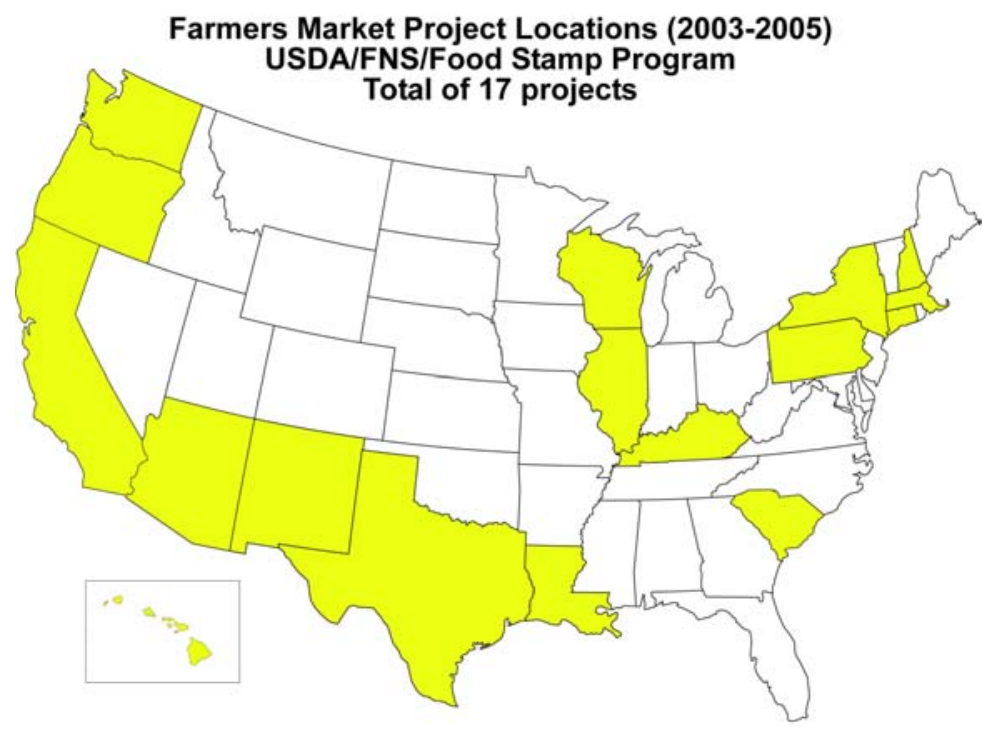

(Back to table of contents) 


\section{USDA - Food and Nutrition Service (FNS) \\ Farmers Market Nutrition Program (FMNP) (View Projects)}

\section{Program Overview}

The Farmers Market Nutrition Program (FMNP) is associated with the Special Supplemental Nutrition Program for Women, Infants and Children—popularly known as WIC—which provides participants with coupons that can be exchanged for fresh fruits, vegetables and herbs at farmers markets and roadside stands. Grants are made to State agencies that, in turn, authorize farmers, markets, and roadside stands to accept the coupons. Additionally, the program assists participants with supplemental foods, health care referrals, and nutrition education at no cost to low-income pregnant and postpartum women, and to infants and children up to 5 years old who are at nutritional risk.

Eligible WIC participants are issued FMNP coupons in addition to their regular WIC food coupons. These coupons can be exchanged for fresh locally grown fruits, vegetables, and herbs from farmers or farmers markets pre-approved by the State agency to accept FMNP coupons, who then submits the coupons to the State for reimbursement.

The Senior Farmers Market Nutrition Program (SFMNP) provides low-income seniors with coupons that can be exchanged for locally grown fruits, vegetables, and herbs from farmers markets, roadside stands, and community-supported agriculture programs. In addition to helping seniors, the program helps increase the domestic consumption of agricultural commodities. It also helps expand farmers markets, roadside stands, and community-supported agriculture. Grants are made to State agencies that, in turn, authorize farmers, markets, and roadside stands and community-supported agriculture groups to accept the coupons.

\section{Contact Information}

Patricia N. Daniels, Director

Supplemental Food Programs Division

USDA/Food Nutrition Service

3101 Park Center Drive, Rm. 520

Alexandria, VA 22302-1500

Phone: (703) 305-2746

\section{Websites}

www.fns.usda.gov/wic/FMNP/FMNPfaqs.htm

www.fns.usda.gov/wic/seniorFMNP/SFMNPmenu.htm

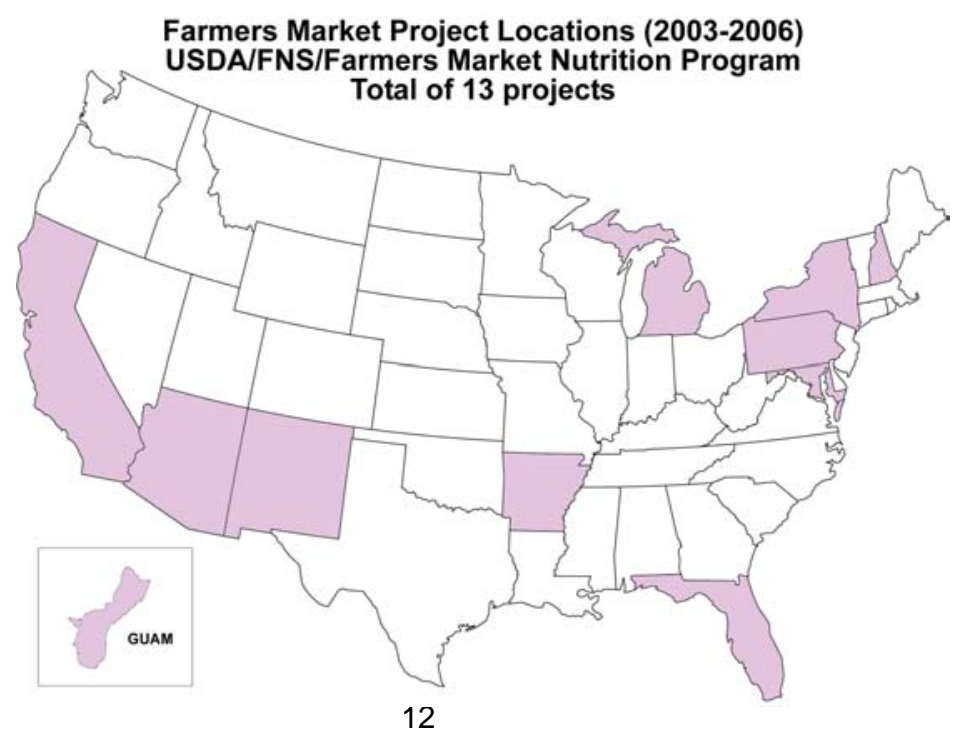




\section{USDA - National Resource Conservation Service (NRCS) Resource Conservation \& Development Program (RC\&D) \\ (View Projects)}

\section{Program Overview}

The Resource Conservation and Development (RC\&D) program provides technical assistance to communities through designated USDA areas led by RC\&D Councils. The program assists conservation efforts and the stewardship and management of natural resources while improving the level of economic activity and standard of living in communities across the nation. RC\&D Councils coordinate conservation and rural development assistance available from USDA, other Federal, State, and local government and nongovernmental sources.

\section{Contact Information}

National Program Office

\section{USDA/NRCS}

National RC\&D Program Manager

Stop 2890, Rm. 6013S

1400 Independence Ave., SW

Washington, D.C. 20250-2890

Phone: (202) 720-0557

Fax: (202) 690-0639

\section{Websites}

www.nrcs.usda.gov/programs/rcd/

www.rcdnet.org

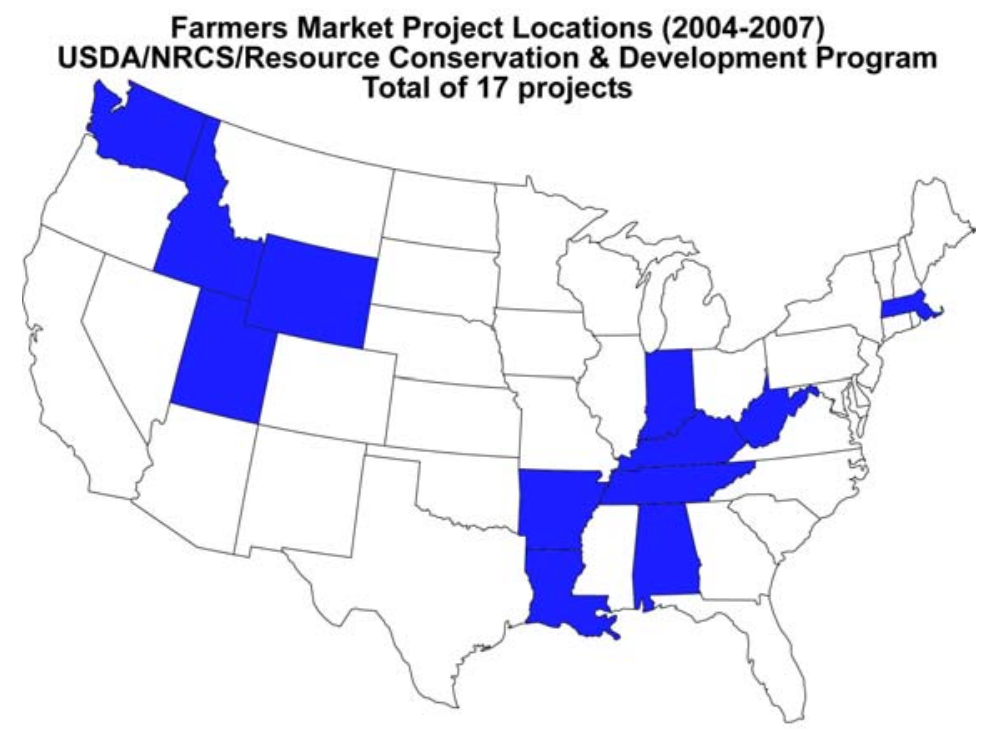

(Back to table of contents) 


\section{USDA - Risk Management Agency (RMA) \\ Outreach Partnership Agreements \\ (View Projects)}

\section{Program Overview}

The Community Outreach and Assistance Partnership Programs ensure that information and technical assistance programs are effectively targeted to women, limited-resource, socially disadvantaged, and other traditionally underserved producers. The RMA maintains an active presence in collaborating with the partners it funds to implement the work designated by its agreements.

Risk management tools aren't limited to insurance products, but include a variety of risk management options and strategies to assist producers in mitigating risks inherent in agricultural production. They may include financial management tools that mitigate price and production risks, tools that enhance measurement and prediction of risks in order to facilitate risk diversification, and tools that improve production management, harvesting, record keeping, or marketing.

\section{Contact Information}

William Buchanan

Community Outreach and Assistance Partnerships

USDA/RMA Sop 0801

1400 Independence Ave., SW

Rm. 6092

Washington, D.C. 20250

Phone: (202) 690-2686

\section{Website}

www.rma.usda.gov

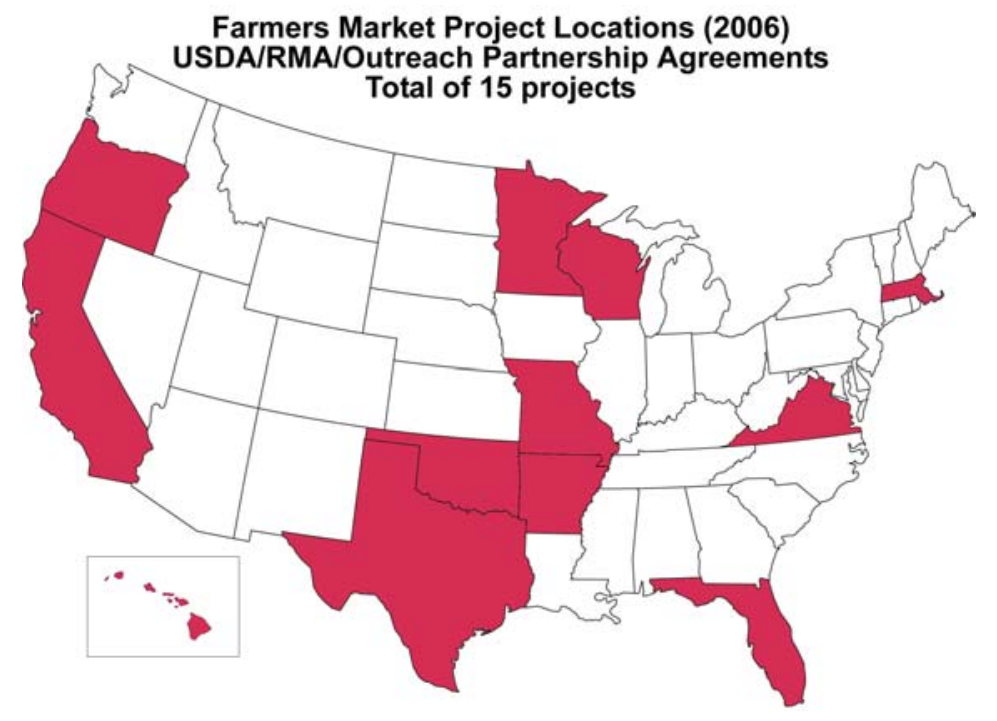

(Back to table of contents) 


\section{USDA - Rural Development (RD) \\ Rural Business Programs (RBS) \\ (View Projects)}

\section{Program Overview}

Rural Development $(R D)$ is committed to increasing economic opportunities for rural residents and improving their quality of life. Through their Rural Business Programs, RD partners with private sector and community-based organizations to provide financial assistance, fund projects that create or preserve jobs and promote a clean rural environment. Financial resources are often leveraged with those of other public and private credit source lenders to meet business and credit needs in underserved areas. Recipients may include individuals, corporations, partnerships, cooperatives, public bodies, nonprofit corporations, Indian tribal governments, and private companies.

\section{Contact Information}

Jody Raskind, Director

Specialty Lenders Division

USDA/RD/RBS

1400 Independence Ave., SW

Rm. 6869

Washington, D.C. 20250

E-mail: Jody.Raskind@usda.gov

\section{Website}

www.rurdev.usda.gov/rbs/

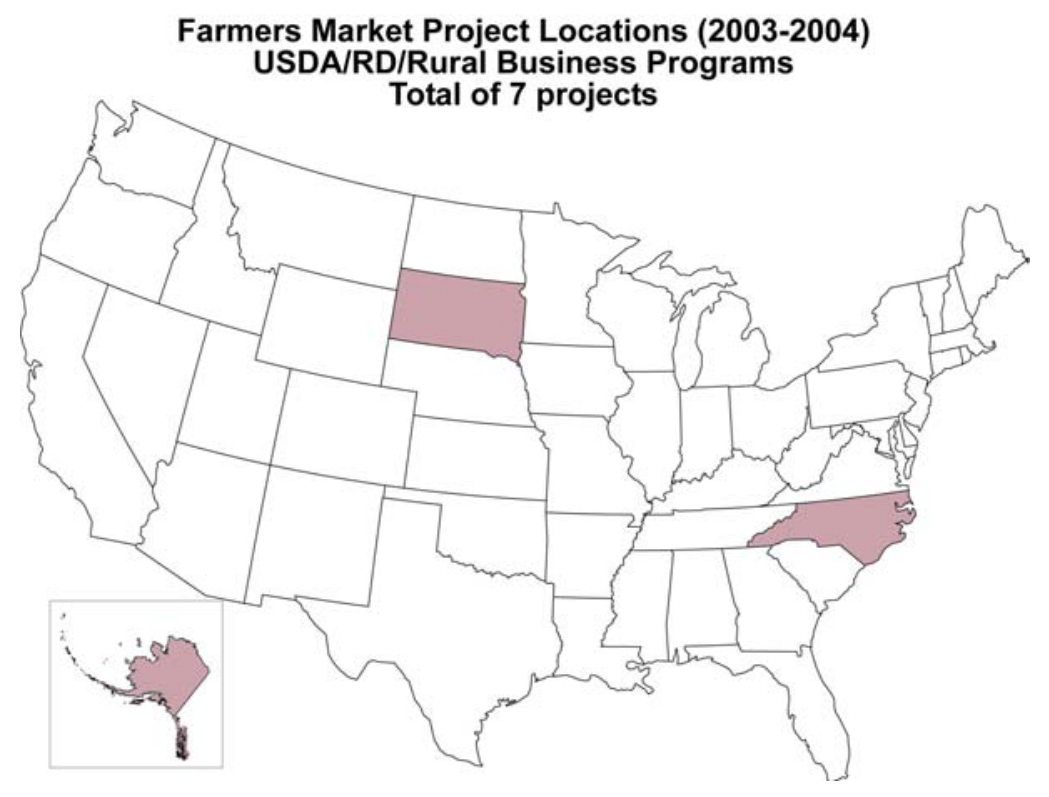

(Back to table of contents) 


\section{USDA - Rural Development (RD) Rural Cooperative Programs (RCS)}

\section{Program Overview}

Rural Cooperative Programs (RCS) promotes the understanding and use of cooperatives as viable business organization options to market and distribute agricultural products. RCS serves cooperative members, directors, management, educational institutions, organizations, rural residents, and all others with an interest in cooperatives. RCS helps them improve their economic well-being and quality of life by marketing through cooperatives. RCS also enters into cooperative agreements with landgrant universities to develop income-producing projects for underserved rural communities. The central focus is on job creation in communities that are traditionally dependent on agriculture.

\section{Contact Information}

Gail Thuner

USDA/RD/RCS

1400 Independence Ave, SW Rm. 4226

Washington, D.C. 20250

Phone: (202) 690-2426

E-mail: Gail.Thuner@wdc.usda.gov

\section{Website}

www.rurdev.usda.gov/rbs/coops/csdir.htm

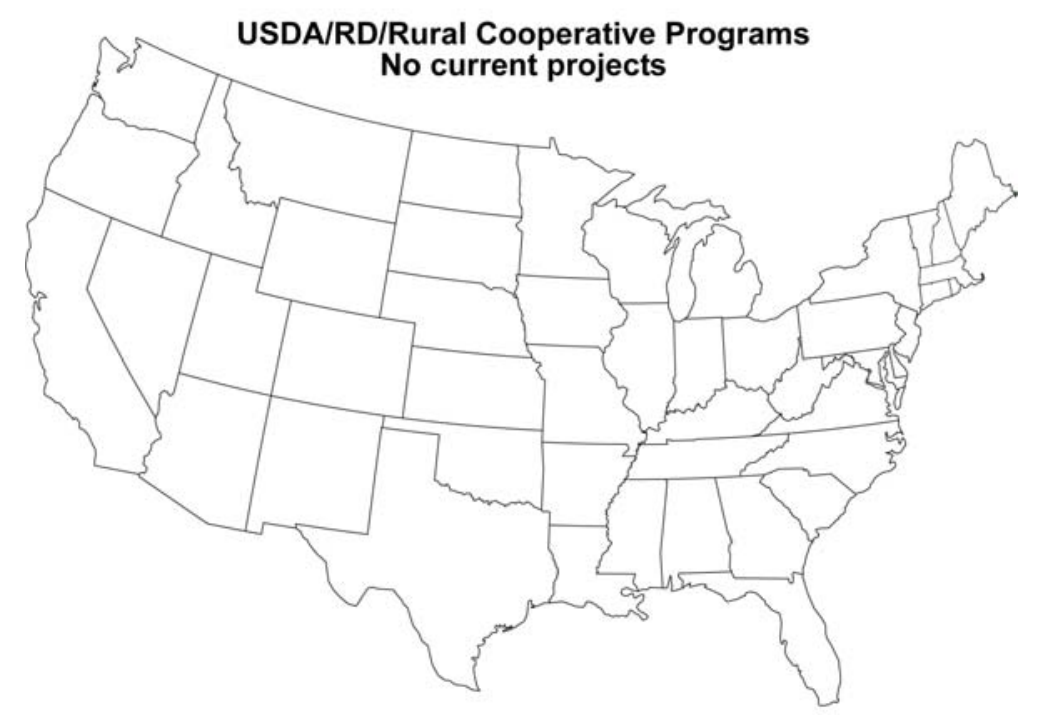

(Back to table of contents) 


\section{Department of Health and Human Services (HHS) Office of Community Services (OCS) \\ (View Projects)}

\section{Program Overview}

The Office of Refugee Resettlement (ORR) within the Department of Health and Human Services administers the domestic Refugee Resettlement Program. The Refugee Agricultural Partnership Program (RAPP) within ORR has a purpose to provide new opportunities for improving the livelihoods of refugee families through agriculture and food sector businesses by engaging in partnerships with federal, state and local public and private organizations that incorporate sound planning and coordination and the utilization of information and social and economic resources. .

Under RAPP, there are no local projects dedicated exclusively to supporting farmers markets. However, because of the widespread use of farmers markets by refugees for selling their produce support for the more effective utilization and improvement of farmers markets is part of a holistic approach to increasing income for refugee farmers.

\section{Contact Information}

Larry Laverentz

ACF/Office of Refugee Resettlement

Phone: (202) 401-4861

\section{Website}

www.acf.hhs.gov/programs/ocs/

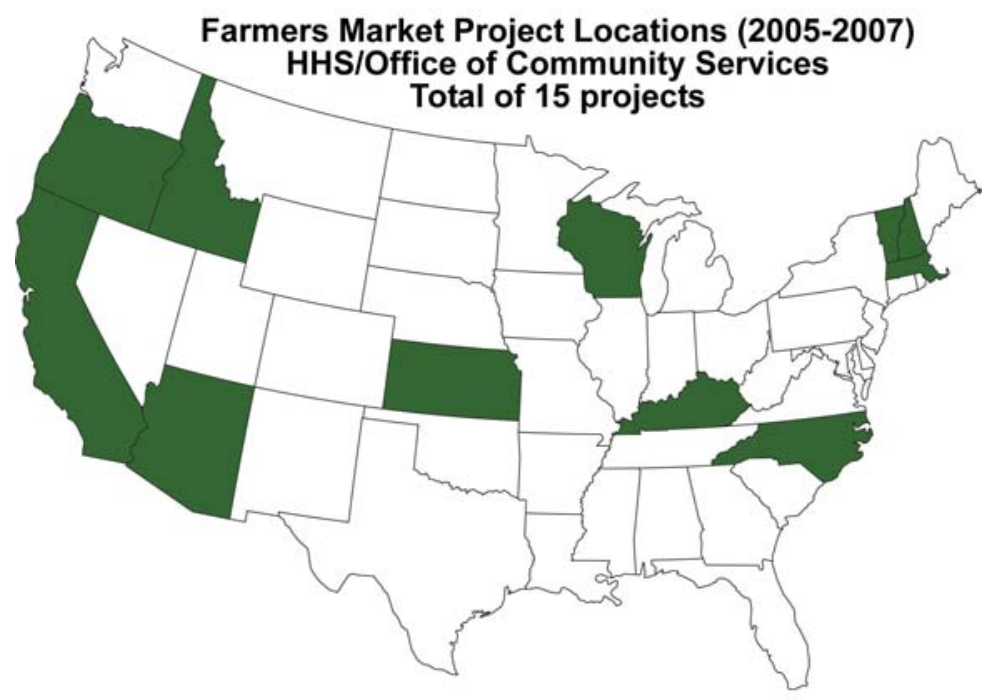

(Back to table of contents) 


\title{
Overview of Private Sector and Foundation Farmers Market Programs
}

\author{
Project for Public Spaces \\ Funding Provided by the Ford Foundation and the W.K. Kellogg Foundation \\ (View Projects)
}

\begin{abstract}
Program Overview
Project for Public Spaces, Inc. (PPS) is a nonprofit organization dedicated to creating and sustaining public places that build communities. PPS provides technical assistance, education, and research through programs in parks, plazas, central squares, civic architecture, transportation, and public markets. Since its founding in 1975, PPS has worked in over 1,500 communities in the United States and around the world, helping people to turn their public spaces into vital community places. PPS has long recognized the catalytic role that markets can play in community development. PPS created its public market program in 1987 to further the preservation and establishment of public markets through research and education programs and through assistance to communities in market development, renewal, design and operations.
\end{abstract}

Since 2002, PPS has been working with the Ford Foundation and, more recently, the W.K. Kellogg Foundation to develop a national funding initiative around public markets and farmers markets. Using a Ford funded research as a departure point, PPS worked with a diverse advisory group of community development experts and public market operators to develop a new paradigm and national funding program for public markets in low- and moderate-income communities. This grant initiative has focused on how public markets and farmers market broaden the social and economic impacts they have on communities; building better places to draw people and catalyze neighborhood revitalization; and simultaneously improving the internal economic sustainability of market operators and vendors. Grants also provide an opportunity for markets to collaborate with organizations and agencies relating to: community and rural development, health and nutrition, neighborhood and downtown interests, local food systems, agriculture, transit, and smart growth, to name a few.

Three rounds of grants have been awarded, one each in 2005, 2006, and 2007.

2005 Grants: In January 2005, PPS awarded grants to nine market projects around the country. This grant round of funding provided support for implementation of projects in larger public markets, as well as planning grants in three cities. A complementary RFP was released by the federal Office of Community Services (OCS), U.S. Department of Health and Human Services to encourage rural and urban community development corporations (CDCs) to create public market projects providing employment and business development opportunities for people with lowincomes.

2006 Grants: The 2006 public markets grant program had a specific focus on farmers markets, and three categories of grants were awarded between January and March 2006: market networks, individual farmers markets, and regional/state farmers market associations.

2007 Grants: The third year of funding, with support from the W.K. Kellogg Foundation, focused exclusively on grants to existing farmers markets in the US and ten markets were awarded grants totaling approximately $\$ 420,000$ in February 2007 . Grants provided markets with the resources to innovate to address broader community issues. Support included not only funding, but also peer networking opportunities, training, and communications expertise to augment outreach efforts, thus building markets' capacity to succeed as effectively run, financially sustainable organizations. The grants also provided markets with the means to forge new partnerships with financial institutions, food pantries, universities, urban agriculture groups, and even a children's museum to provide opportunities for youth, immigrants, and disadvantaged individuals to expand 
their customer base and to better serve low-income shoppers and ethnically diversifying populations.

Individual Farmers Market Mini-Grants: These mini-grants assisted individual farmers markets in fostering innovation at the local level, addressing issues of food security, promoting health and nutrition and community development, and building new partnerships. Grants provided markets with the resources to innovate to address broader community issues. Support included not only funding, but also peer networking opportunities, training, and communications expertise to augment outreach efforts, thus building markets' capacity to succeed as effectively run, financially sustainable organizations.

\section{Contact Information}

Project for Public Spaces

Chris Heitmann

Senior Project Manager

700 Broadway, 4th Fl.

New York, NY 10003

Phone: (212) 620-5660

E-mail : cheitmann@pps.org

\section{Websites}

www.pps.org/

www.farmersmarketsusa.org/

Farmers Market Project Locations (2005)

Project for Public Spaces with Funding by the Ford Foundation Total of 9 projects

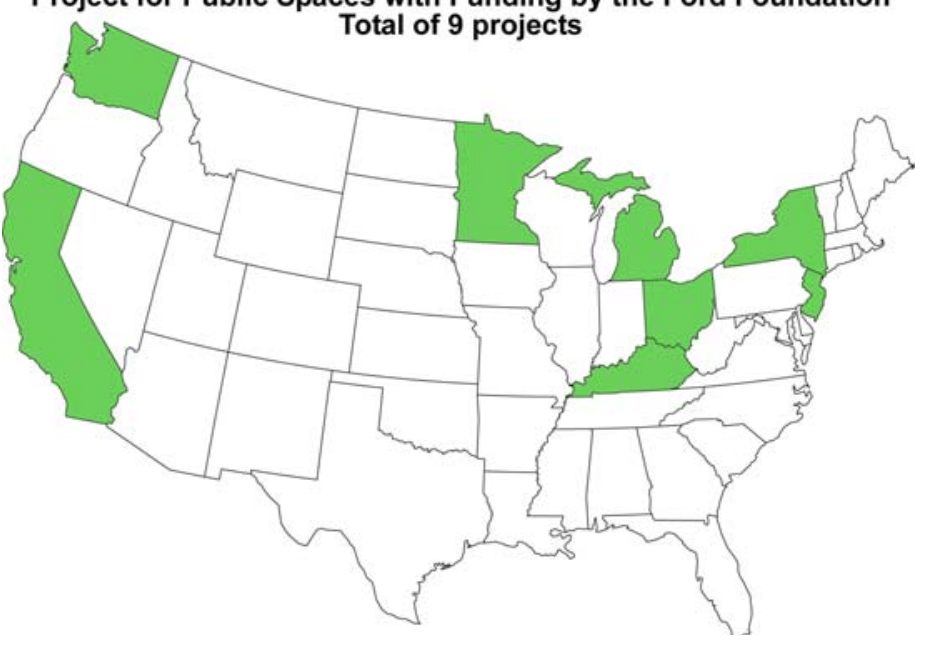

Farmers Market Project Locations (2006-2007)

Market Network Grants

Project for Public Spaces

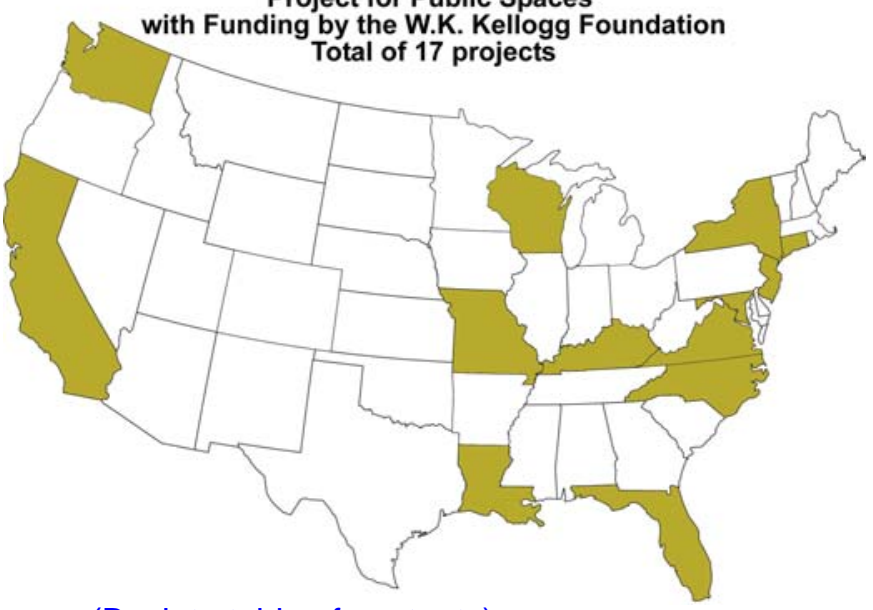

19
Ford Foundation

Miguel Garcia

Phone: (212) 573-4618

E-mail: M.Garcia@fordfound.org
Kellogg Foundation

Gus Schumacher

Phone: (202) 549-3308

E-mail Gussch@aol.com

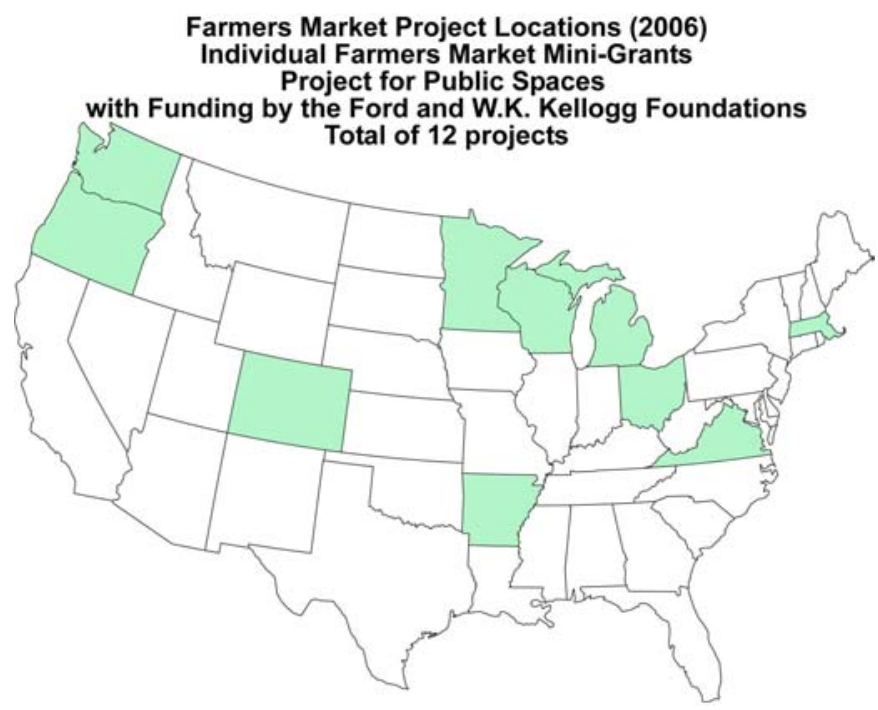

Farmers Market Project Locations (2006) State/Regional Market Association Grants Project for Public Spaces with Funding by the W.K. Kellogg Foundation

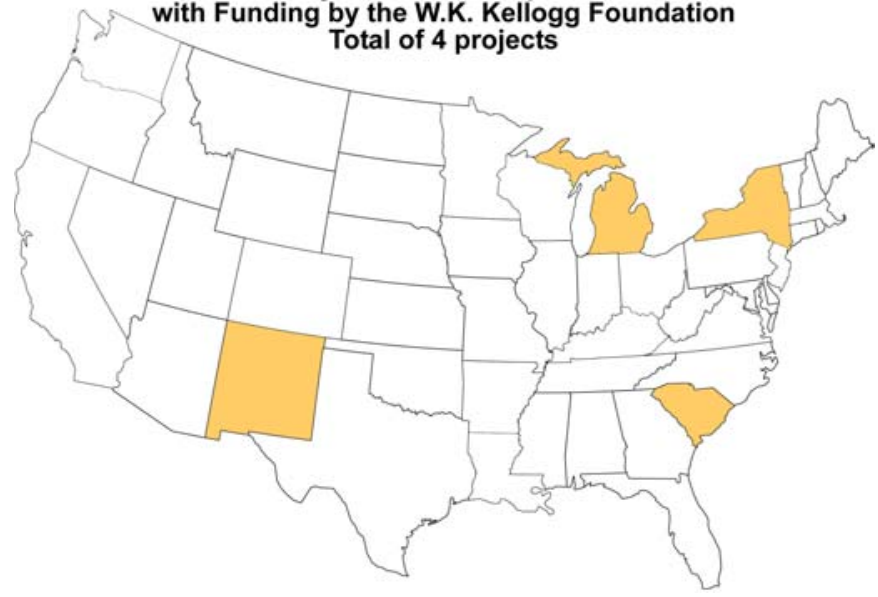




\section{Federal Farmers Market Projects}

\section{USDA - Agricultural Marketing Service (AMS) \\ Transportation and Marketing Programs/Marketing Services Branch (TM/MSB) (View Program Description)}

\section{Arizona}

Project Type: Market Development

Year: 2004

Grantor: TM/MSB

Grantee/Cooperator: Arizona State - Phase II

Grant Matching: N/A

Funding: Cooperative Agreement $(\$ 30,500)$

Total: $\$ 30,500$

Objective: To study the feasibility of developing a year-round farmers market in downtown Phoenix. The assistance included the review of design proposals for the establishment of a temporary market facility with a 5,000 sq. $\mathrm{ft}$. canopy to provide cover for 40 vendors.

\section{Connecticut}

Project Type: Consumer Education and Access

Year: 2005

Grantor: TM/MSB

Grantee/Cooperator: City Seed Inc., New Haven, Connecticut

Grant Matching: N/A

Funding: Cooperative Agreement $(\$ 20,000)$

Total: $\$ 20,000$

Objective: To prepare a feasibility study for the development of a year-round farmers market in New Haven, Connecticut. Additional objectives of the study include: (a) Preparing site selection criteria and assisting in the selection of sites for analysis; (b) Conducting a market training presentation for the project working group and advisory committee; (c) Developing a conceptual plan for each of three preferred sites; and (d) Preparing and presenting a short report with preliminary physical and economic analyses of the preferred sites and recommendations for the next steps in the feasibility process.

\section{District of Columbia}

Project Type: Market Development

Year: 2007

Grantor: TM/MSB

Grantee/Cooperator: Institute of Social and Economic Development

Funding: $\$ 10,000$

Grant Matching: N/A

Total: $\$ 10,000$

Objective: To analyze the workings of several alternative distribution models and assess their effectiveness in improving the economic welfare of small-scale and limited-resource producers through more direct marketing of agricultural products.

\section{Florida}

Project Type: Market Development

Year: 2004

Grantor: TM/MSB

Grantee/Cooperator: Florida Department of Agriculture and Consumer Services

Grant Matching: N/A

Funding: Cooperative Agreement $(\$ 80,000)$

Total: $\$ 80,000$

Objective: To analyze data obtained in an initial survey of existing and damaged market structures to assess the 
damage to Fort Pierce State Farmers Market, which was extensively damaged by Hurricane Frances. Assisted in identifying demolition plans, provided technical architectural review of reconstruction plans and specification, and provided costs estimates and recovery plans in time to secure a financial commitment from the Federal Emergency Management Agency.

lowa

Project Type: Market Development

Year: 2007

Grantor: TM/MSB

Grantee/Cooperator: Farmers Market Coalition

Funding: $\$ 40,000$

Grant Matching: N/A

Total: $\$ 40,000$

Objective: To research and identify opportunities and resources to help build capacity and strengthen farmers markets throughout the US.

Project Type: Producer Training and Support

Year: 2006

Grantor: TM/MSB

Grantee/Cooperator: Farmers Market Coalition

Grant Matching: N/A

Funding: Cooperative Agreement $(\$ 55,000)$

Total: $\$ 55,000$

Objective: To establish and stabilize an independent, national organization, the Farmers Market Coalition, to strengthen farmers markets for the benefit of farmers, consumers, and communities. Specific strategies to accomplish this objective include: sponsoring a series of strategic planning meetings and educational workshops; developing a 5-year action plan for FMC; establishing an effective FMC communications network to coordinate FMC activities; providing educational programming and networking opportunities that work with and support farmers markets; and coordinating opportunities to address farmers market managers concerns.

Project Type: Market Promotion

Year: 2004

Grantor: TM/MSB

Grantee/Cooperator: Drake University Agricultural Law School

Grant Matching: N/A

Funding: Cooperative Agreement $(\$ 5,000)$

Total: $\$ 5,000$

Objective: To convene a national workshop on State and local food policy conference, The Role of Farmers in America's Food System. The conference aims to organize and engage groups of small farmers, market managers, food processors and marketers, government officials and others to discuss about food and agricultural policy opportunities.

\section{Louisiana}

Project Type: Market Development

Year: 2005

Grantor: TM/MSB

Grantee/Cooperator: Loyola University, Economic Institute, New Orleans

Grant Matching: N/A

Funding: Cooperative Agreement $(\$ 0)$ Technical and Marketing Assistance

Total: $\$ 0$

Objective: To provide technical and marketing assistance to farmers, farmers market managers, and other market sponsors to restart farmers markets and other direct marketing enterprises affected by Hurricane Katrina.

Project Type: Market Promotion

Year: 2004

Grantor: TM/MSB

Grantee/Cooperator: Louisiana RC\&D Council, Crescent City Farmers Market, New Orleans

Grant Matching: N/A

Funding: Cooperative Agreement $(\$ 10,000)$

Total: $\$ 10,000$

Objective: To convene a 4-M (Mission, Marketing, Management, and Measurement) Farmers Market Training 
Conference. The conference provided targeted training on direct farm marketing to small farm producers and current farmers market tenants in the Southeast region.

\section{Massachusetts}

Project Type: Market Promotion

Year: 2004

Grantor: TM/MSB

Grantee/Cooperator: North American Direct Farmers Market Association (NADFMA)

Grant Matching: N/A

Funding: Cooperative Agreement $(\$ 90,000)$

Total: $\$ 90,000$

Objective: Assist the North American Farmers Direct Marketing Association (NAFDMA) and the Farmers Coalition (FMC) in: (a) Sponsoring and assisting in the planning of the annual meeting; (b) Planning and coordinating five regional training and informational workshops; (c) Cosponsoring a Farmer Market Policy Summit; and (d) Establishing an FMC communications network to coordinate activities and farmers market managers concerns.

\section{Michigan}

Project Type: Market Development

Year: 2007

Grantor: TM/MSB

Grantee/Cooperator: Market Analysis

Funding: $\$ 40,000$

Match: N/A

Total: $\$ 40,000$

Objective: To study the characteristics and performance of farmers markets in order to better assist farmers markets, both in terms of how to set up initial operations, and how best to improve market performance in latter stages.

\section{Mississippi}

Project Type: Producer Training and Support

Year: 2003

Grantor: TM/MSB

Grantee/Cooperator: LeFleur's Bluff State Farmers Market, Jackson

Grant Matching: N/A

Funding: Cooperative Agreement $(\$ 35,000)$

Total: $\$ 35,000$

Objective: To work with the Mississippi State University Food and Fiber Center to conduct a consumer survey to assess which products and amenities the residents of the Jackson metropolitan region would find appealing in the new market. TM/MSB provided technical support and guidance for a series of producer training sessions designed to introduce farmers to successful direct marketing practices including commodity selection, effective display and signage practices, and building relationships with customers.

\section{New York}

Project Type: Market Development

Year: 2004

Grantor: TM/MSB

Grantee/Cooperator: New York State Department of Agriculture and Marketing

Grant Matching: N/A

Funding: Cooperative Agreement $(\$ 50,000)$

Total: $\$ 50,000$

Objective: To further study the development of a wholesale buyer-oriented farmers market facility in New York City, and provide an additional $\$ 60,000$ to support a second phase of research. 


\section{North Carolina}

Project Type: Producer Training and Support

Year: 2005

Grantor: TM/MSB

Grantee/Cooperator: North Carolina A\&T University

Grant Matching: N/A

Funding: Cooperative Agreement $(\$ 10,000)$

Total: $\$ 10,000$

Objective: To host the $4^{\text {th }}$ National Small Farms Conference in Greensboro, North Carolina (October, 2005). The conference was attended by farmers and farm managers, agricultural specialists, State departments of agriculture personnel, land-grant university personnel and other small-farm service providers.

\section{Oregon}

Project Type: Market Development

Year: 2003

Grantor: TM/MSB

Grantee/Cooperator: Portland Oregon Public Farmers Market

Grant Matching: N/A

Funding: Cooperative Agreement $(\$ 70,000)$

Total: $\$ 70,000$

Objective: To assess the feasibility of developing a year-round public/farmers market in downtown Portland, Oregon.

\section{Pennsylvania}

Project Type: Consumer Education and Access

Year: 2005

Grantor: TM/MSB

Grantee/Cooperator: Southeastern Pennsylvania Resource Conservation and Development Council (SEPA RC\&D) Grant Matching:

Funding: Cooperative Agreement $(\$ 50,000)$

Total: $\$ 50,000$

Objective: To study the feasibility of providing transportation services to participants in the Farmers Market Nutrition Program (FMNP, Seniors Farmers Nutrition Program and Women, Infant, and Children programs), and other senior citizens, ethnic minorities, and low-income residents, to farmers markets in Southeastern Pennsylvania.

\section{(Back to table of contents)}




\section{USDA - Agricultural Marketing Service (AMS) \\ Farmers Market Promotion Program (FMPP) \\ (View Program Description)}

\section{Arizona}

Project Type: Market Development

Year: 2006

Grantor: FMPP

Grantee/Cooperator: Natwani Coalition/Hopi Foundation, Kykotsmovi, AZ

Grant Matching: N/A

Funding: Cooperative Agreement $(\$ 19,421)$

Total: $\$ 19,421$

Objective: To help sustain a farmers market on the Hopi reservation through innovative cooperative transportation of produce that will improve access and availability for market patrons.

\section{Arkansas}

Project Type: Market Development

Year: 2007

Grantor: FMPP

Grantee/Cooperator: East Arkansas Resource Conservation and Development Council, Inc

Funding: $\$ 45,666$

Grant Matching: $\$ 23,564$

Total: $\$ 69,230$

Objective: To research farmers' and customers' needs and create educational programs for farm vendors at the ASU

Regional Farmers Market on business practices and crop planning.

Project Type: Market Development

Year: 2006

Grantor: FMPP

Grantee/Cooperator: City of Hot Springs, AR

Grant Matching: N/A

Funding: Cooperative Agreement $(\$ 52,918)$

Total: $\$ 52,918$

Objective: To encourage greater diversity of both vendors and customers at the local farmers market, address

infrastructure shortcomings that impede vendor and consumer participation in the market, and to improve the access of lower-income consumers to fresh food through an increased focus on WIC/Senior Farmers Market Nutrition Program coupon redemption, food stamp redemption, and nutritional education programs.

\section{California}

Project Type: Market Development

Year: 2007

Grantor: FMPP

Grantee/Cooperator: Agriculture and Land-Based Training Association, Salinas

Funding: $\$ 49,275$

Grant Matching: $\$ 30,000$

Total: $\$ 79,275$

Objective: To develop four new farmers markets and four church-based farm stands which target culturally diverse and health distressed communities. Funds also will be used to provide training and technical assistance to limited-resource farmers and implement outreach and education programs to expand demand for direct-marketed products. 
Project Type: Market Development

Year: 2007

Grantor: FMPP

Grantee/Cooperator: Mendocino County Farmers' Market Association, Fort Bragg

Funding: $\$ 35,617$

Grant Matching: N/A

Total: $\$ 35,617$

Objective: To establish community supported agriculture at five farmers markets, expand two existing ones and implement an outreach and educational campaign to broaden the customer base at the Association's eight farmers markets.

Project Type: Market Promotion

Year: 2006

Grantor: FMPP

Grantee/Cooperator: Pacific Coast Farmers Market Association, Concord, CA

Grant Matching: N/A

Funding: Cooperative Agreement $(\$ 70,000)$

Total: $\$ 70,000$

Objective: To test various promotional strategies and to determine which combinations of community outreach and media use are the most cost-effective in encouraging consumers to patronize local farmers markets.

Project Type: Market Development

Year: 2006

Grantor: FMPP

Grantee/Cooperator: Davis Farmers Market Foundation, Davis, CA

Grant Matching: N/A

Funding: Cooperative Agreement $(\$ 41,800)$

Total: $\$ 41,800$

Objective: To create new marketing opportunities for the current vendors at the Davis Farmers Market by developing an innovative partnership with the Davis Joint Unified School District.

\section{Colorado}

Project Type: Producer Training and Support

Year: 2006

Grantor: FMPP

Grantee/Cooperator: Colorado Farmers Market Association, Boulder, CO

Grant Matching: N/A

Funding: Cooperative Agreement $(\$ 57,930)$

Total: $\$ 57,930$

Objective: To assist farmers markets in Colorado in implementing electronic benefits transfers (EBT) that will aid in increasing food stamp redemptions at local farmers markets, thus allowing greater consumption of fresh fruit and vegetables by lower-income consumers.

\section{District of Columbia}

Project Type: Market Development

Year: 2007

Grantor: FMPP

Grantee/Cooperator: Food Research and Action Center

Funding: $\$ 41,312$

Grant Matching: N/A

Total: $\$ 41,312$

Objective: To develop EBT (electronic benefits transfer) infrastructure for four farmers markets in the District, and provide EBT training to farmers market staff. 


\section{Florida}

Project Type: Producer Training and Support

Year: 2006

Grantor: FMPP

Grantee/Cooperator: Florida Association of Community Farmers Market, Daytona, FL

Grant Matching: N/A

Funding: Cooperative Agreement $(\$ 63,238)$

Total: $\$ 63,238$

Objective: To develop baseline data on the economic and demographic characteristics of Florida farmers markets; to provide training to Florida farmers who may need assistance in transitioning from selling to wholesale buyers to supplying household consumers; to train farmers market managers in identifying and recruiting local growers to participate in community farmers markets; and to expand consumer awareness of locally grown farm products through promotional activities.

Hawaii

Project Type: Market Development

Year: 2007

Grantor: FMPP

Grantee/Cooperator: Hawaii Farm Bureau Federation of Honolulu

Funding: $\$ 29,300$

Grant Matching: N/A

Total: $\$ 29,300$

Objective: To establish and promote a new producer-only farmers market in Waianae, Oahu, that will offer fresh fish and agricultural products, which will provide farmers and fishers in the area a new direct-to-consumer market channel.

\section{Idaho}

Project Type: Market Development

Year: 2007

Grantor: FMPP

Grantee/Cooperator: Hagerman I.D.E.A. (Improvement, Development, Education and Appreciation), Inc.

Funding: $\$ 60,294$

Grant Matching: $\$ 28,993$

Total: $\$ 89,287$

Objective: To create an agricultural marketing cooperative where producers sell their own products directly to consumers via the Internet.

Illinois

Project Type: Market Promotion

Year: 2006

Grantor: FMPP

Grantee/Cooperator: Oswegoland Park District, Oswego, IL

Grant Matching: N/A

Funding: Cooperative Agreement $(\$ 8,640)$

Total: $\$ 8,640$

Objective: To recruit more farmer vendors and customers for its recently created community farmers market through advertising, community outreach, and promotion.

\section{Indiana}

Project Type: Market Development

Year: 2007

Grantor: FMPP

Grantee/Cooperator: City of West Lafayette

Funding: $\$ 38,000$ 
Grant Matching: $\$ 8,550$

Total: $\$ 46,550$

Objective: To establish a "Green and Lean" marketing program at the Sagamore West Farmers' Market that will include an advertising campaign with educational materials for vendors and consumers to promote healthy eating, physical fitness and personal safety.

Project Type: Market Development

Year: 2007

Grantor: FMPP

Grantee/Cooperator: Plainfield Chamber of Commerce

Funding: $\$ 15,844$

Grant Matching: N/A

Total: $\$ 15,844$

Objective: To establish a second farmers market at the Metropolis Mall, with promotional advertising, consumer-based education to attract customers and enhance the viability of the new market location.

\section{lowa}

Project Type: Market Development

Year: 2007

Grantor: FMPP

Grantee/Cooperator: Golden Hills Resource Conservation and Development of Oakland

Funding: $\$ 8,128$

Grant Matching: $\$ 6,282$

Total: $\$ 14,410$

Objective: To establish and promote the new Riverside Farmers Market through advertising to consumers, farmer recruitment and training and educational events that link fresh food with community health and wellness.

Project Type: $\underline{\text { Market Promotion }}$

Year: 2006

Grantor: FMPP

Grantee/Cooperator: City of Silver City, IA

Grant Matching: N/A

Funding: Cooperative Agreement $(\$ 7,848)$

Total: $\$ 7,848$

Objective: To increase the number of farmer vendors and to expand the customer base of the Silver City Market through implementation of promotional strategies that increase market visibility and accessibility.

\section{$\underline{\text { Massachusetts }}$}

Project Type: Market Development

Year: 2006

Grantor: FMPP

Grantee/Cooperator: Community Involved in Sustaining Agriculture, Inc., South Deerfield, MA

Grant Matching: N/A

Funding: Cooperative Agreement $(\$ 61,275)$

Total: $\$ 61,275$

Objective: To develop a new direct marketing channel for farmers by creating a community supported agriculture (CSA) program for workplace employees in western Massachusetts, while providing training and hands-on agricultural production and marketing experiences for new immigrant farmers and other small-scale agriculture producers.

\section{Michigan}

Project Type: Market Development

Year: 2007

Grantor: FMPP

Grantee/Cooperator: City of Bad Axe Department of Parks \& Recreation

Funding: $\$ 8,430$

Grant Matching: $\$ 6,500$

Total: $\$ 14,930$ 
Objective: To advertise and promote campaign activities to increase patronage at the Bad Axe Farmers Market, which is located near the intersection of two major roads with substantial tourist traffic.

Project Type: Consumer Education and Access

Year: 2006

Grantor: FMPP

Grantee/Cooperator: Central Macomb Chamber of Commerce, Mount Clemens, MI

Grant Matching: N/A

Funding: Cooperative Agreement $(\$ 24,140)$

Total: $\$ 24,140$

Objective: To develop a more thorough understanding of customer shopping habits at a largely volunteer-run community farmers market; to increase the market's visibility through various signage, advertising and communication strategies; and to provide a more sustainable source of farm-based income for regional horticultural growers threatened by urban sprawl.

\section{Missouri}

Project Type: Market Development

Year: 2007

Grantor: FMPP

Grantee/Cooperator: Top of the Ozarks Resource Conservation \& Development

Funding: $\$ 70,150$

Grant Matching: N/A

Total: $\$ 70,150$

Objective: To assess the needs of 12 farmers markets in 10 South Central Missouri counties; determine how to best meet these needs; and improve visibility of the markets through advertising, product mix, infrastructure improvements, vendor training and communication.

\section{New Mexico}

Project Type: Consumer Education and Access

Year: 2006

Grantor: FMPP

Grantee/Cooperator: New Mexico Farmers Marketing Association, Santa Fe, NM

Grant Matching: N/A

Funding: Cooperative Agreement $(\$ 68,550)$

Total: $\$ 68,550$

Objective: To boost the volume of locally grown fruit, vegetable and tree nut crops available for sale at New Mexico's farmers markets through targeted technical assistance; to introduce wireless EBT technology to farmers markets in four rural counties in New Mexico that suffer high rates of poverty, in order to improve access to fresh fruits and vegetables among Hispanic, Native American, and Anglo residents of lower-income communities that receive food stamp benefits; to help sustain a new senior farmers market nutrition voucher project that has yielded encouraging results to date; and to develop the capacity of new and emerging farmers markets throughout the state by offering competitive mini-grants for facility improvements.

\section{New York}

Project Type: Consumer Education and Access

Year: 2006

Grantor: FMPP

Grantee/Cooperator: Council on the Environment, New York City, NY

Grant Matching: N/A

Funding: Cooperative Agreement $(\$ 66,000)$

Total: $\$ 66,000$

Objective: To evaluate the impact of wireless EBT terminals on the ability of inner-city farmers market vendors to tap more successfully into the estimated $\$ 1$ billion in benefits received by food stamp recipients in New York City each year, and to encourage greater patronage of farmers markets by lower-income households. 
Project Type: Producer Training and Support

Year: 2006

Grantor: FMPP

Grantee/Cooperator: Cooperative Extension Association, Madison County, NY

Grant Matching: N/A

Funding: Cooperative Agreement $(\$ 29,829)$

Total: $\$ 29,829$

Objective: To improve the ability of Agricultural Extension Agents to provide relevant assistance to farmers market managers and vendors in their communities through the development of targeted training materials.

\section{North Carolina}

Project Type: Market Development

Year: 2006

Grantor: FMPP

Grantee/Cooperator: Ashe County Partnership for Children, Jefferson, NC

Grant Matching: N/A

Funding: Cooperative Agreement $(\$ 45,235)$

Total: $\$ 45,235$

Objective: To acquire specialized equipment for a planned 2,500 square foot shared-use commercial kitchen that will enable local producers to bake and process local food products including fried and baked pies, jams, jellies and fruit butters, applesauce and dried fruit snacks, from lesser-grade fruit that cannot be sold profitably through fresh market channels

\section{Ohio}

Project Type: Market Development

Year: 2007

Grantor: FMPP

Grantee/Cooperator: Small Farm Institute at Fresno

Funding: $\$ 32,572$

Grant Matching: N/A

Total: $\$ 32,572$

Objective: To help grass-based beef producers market their products directly to consumers at farmers markets by conducting a series of workshops to identify strategies for production, processing, preparation and marketing grass-fed beef products.

\section{Oklahoma}

Project Type: Market Development

Year: 2007

Grantor: FMPP

Grantee/Cooperator: Oklahoma Black Historical Research Project, Inc.

Funding: $\$ 62,270$

Grant Matching: $\$ 5,000$

Total: $\$ 67,270$

Objective: To establish, promote and manage the Eastside Farmers Market in an inner-city Oklahoma City neighborhood, and train more than 250 small, limited-resource farmers in 44 counties to market their produce at farmers markets throughout the state.

Project Type: Market Development

Year: 2007

Grantor: FMPP

Grantee/Cooperator: Oklahoma Food Cooperative of Oklahoma City

Funding: $\$ 66,200$

Grant Matching: N/A

Total: $\$ 66,200$

Objective: To enhance its distribution system with better transportation and computerized recordkeeping equipment so it can expedite the delivery of produce using a web-based marketing and ordering system for regional producers. 


\section{Oregon}

Project Type: Market Development

Year: 2007

Grantor: FMPP

Grantee/Cooperator: Rogue Initiative for a Vital Economy of Ashland

Funding: $\$ 26,500$

Grant Matching: $\$ 39,500$

Total: $\$ 66,000$

Objective: To locate and design two permanent Jackson County farmers market sites based on surveys of vendors, as

well as current and future customers, in order to meet customer demand and increase direct farm sales in Southern

Oregon.

Project Type: Market Development

Year: 2007

Grantor: FMPP

Grantee/Cooperator: Adelante Mujeres of Forest Grove

Funding: $\$ 47,236$

Grant Matching: $\$ 34,996$

Total: $\$ 82,232$

Objective: To purchase and implement EBT/debit/credit technology, provide training and marketing support to Hispanic and other minority farmers and vendors and develop a marketing plan to attract low-income and senior citizen customers.

Project Type: Market Development

Year: 2006

Grantor: FMPP

Grantee/Cooperator: Oregon Health and Science University Foundation, Portland, OR

Grant Matching: N/A

Funding: Cooperative Agreement $(\$ 10,000)$

Total: $\$ 10,000$

Objective: To develop a farmers market at a teaching hospital campus that employs more than 11,000 individuals and treats more than 180,000 patients annually, serving as a platform to incorporate more locally grown food into the university's cafeteria menus and promote healthier eating habits among community residents through nutrition education.

Project Type: Market Promotion

Year: 2006

Grantor: FMPP

Grantee/Cooperator: Oregon Rural Action, La Grande, OR

Grant Matching: N/A

Funding: Cooperative Agreement $(\$ 67,692)$

Total: $\$ 67,692$

Objective: To analyze and identify the economic, geographic and infrastructural factors that have contributed to the longterm success and failure of various farmers markets in the State of Oregon, and explore the role(s) that a statewide farmers market association might be able to play in enhancing the stability of farmers market operations through networking, information exchange, and strategic planning.

\section{Pennsylvania}

Project Type: Market Development

Year: 2007

Grantor: FMPP

Grantee/Cooperator: Penn's Corner Farm Alliance of Pittsburgh

Funding: $\$ 45,000$

Grant Matching: $\$ 10,000$

Total: $\$ 55,000$

Objective: To purchase refrigerated storage and other necessary equipment to improve the farm cooperative's infrastructure capacity to serve its current distribution channels.

Project Type: Market Development

Year: 2007

Grantor: FMPP

Grantee/Cooperator: Food Trust of Philadelphia

Funding: $\$ 23,091$

Grant Matching: N/A

Total: $\$ 23,091$ 
Objective: To implement a pilot program that will develop and evaluate a model for EBT/credit/debit sales and train vendors in its use at the Clark Park Farmers Market in west Philadelphia, and implement a marketing campaign to increase patronage by food stamp recipients and other underserved consumers.

\section{Rhode Island}

Project Type: Market Development

Year: 2007

Grantor: FMPP

Grantee/Cooperator: Farm Fresh Rhode Island of Providence

Funding: $\$ 50,000$

Grant Matching: $\$ 44,000$

Total: $\$ 94,000$

Objective: To standardize market branding and applications at nine farmers markets; create a market manager's guide that will include standardized market operational tasks and rules; and purchase wireless EBT terminals, bilingual signage, advertisements and other promotional material to help increase farmers' sales to customers.

\section{South Carolina}

Project Type: Market Development

Year: 2007

Grantor: FMPP

Grantee/Cooperator: Downtown Brookings, Inc.

Funding: $\$ 34,884$

Grant Matching: $\$ 17,200$

Total: $\$ 52,084$

Objective: To provide annual training to vendors in food safety, advertising, display, transportation and marketing at farmers markets; offer seasonal training and demonstrations to consumers in food handling and nutrition; and conduct surveys of vendors and customers to assess the effectiveness of project activities.

Project Type: Market Promotion

Year: 2006

Grantor: FMPP

Grantee/Cooperator: Clemson University, Clemson, SC

Grant Matching: N/A

Funding: Cooperative Agreement $(\$ 20,264)$

Total: $\$ 20,264$

Objective: To attract more customers and vendors to a historic county farmers market in order to improve farm-based income and to improve consumer access to fresh fruits and vegetables in a very rural, racially diverse community where a sizable segment of households (21 percent) live below the poverty line.

\section{$\underline{\text { Texas }}$}

Project Type: Market Development

Year: 2007

Grantor: FMPP

Grantee/Cooperator: The University of Texas - Pan American in Edinburg

Funding: $\$ 62,643$

Grant Matching: N/A

Total: $\$ 62,643$

Objective: To conduct research on the long-term feasibility of farmers markets in the region and to develop strategic planning and management practices, database access, training and other best practices for farmers markets comprised primarily of Hispanic farmers and consumers.

Project Type: Market Development

Year: 2006

Grantor: FMPP

Grantee/Cooperator: Sunset Valley Farmers Market of Sunset Valley, TX

Grant Matching: N/A

Funding: Cooperative Agreement $(\$ 67,950)$ 
Total: $\$ 67,950$

Objective: To design a permanent farmers market facility for the community that incorporates conservation and environmentally sustainable principles in its architectural and design elements, in order to enhance the efficiency, utility, and visual appeal of the farmers market structure.

$\underline{\text { Utah }}$

Project Type: Market Development

Year: 2007

Grantor: FMPP

Grantee/Cooperator: Downtown Alliance of Salt Lake City

Funding: $\$ 15,893$

Grant Matching: N/A

Total: $\$ 15,893$

Objective: To pilot an alternative purchase program to purchase and utilize EBT and food stamp payment systems and design and implement a training and educational program for farmers market managers, more than 100 farm vendors, and food stamp recipients, to increase fresh food access and farmer sales.

\section{Vermont}

Project Type: Producer Training and Support

Year: 2006

Grantor: FMPP

Grantee/Cooperator: Northeast Organic Farming Association of Vermont, Richmond, VT

Grant Matching: N/A

Funding: Cooperative Agreement $(\$ 62,538)$

Total: $\$ 62,538$

Objective: To improve the profitability of direct-to-consumer farm marketing activities in Vermont by conducting an assessment of existing direct marketing channels for farm products; to provide technical training to local producers on value-added product development, merchandise displays, and market development for fall/winter crops; and to developing the technical capacity of Vermont farmers markets to accept food stamps.

\section{Washington}

Project Type: Market Development

Year: 2007

Grantor: FMPP

Grantee/Cooperator: Spokane Farmers' Market Association

Funding: \$31,695

Grant Matching: $\$ 8,500$

Total: $\$ 40,195$

Objective: To use promotional activities in establish on-site consumer nutrition education, particularly to low-income families and improve vendor sales through the establishment of EBT/credit/debit technology.

\section{$\underline{\text { Wisconsin }}$}

Project Type: Producer Training and Support

Year: 2006

Grantor: FMPP

Grantee/Cooperator: Dunn County Economic Development Corporation, Menomonie, WI

Grant Matching: N/A

Funding: Cooperative Agreement $(\$ 54,732)$

Total: $\$ 54,732$

Objective: To significantly increase the income of small-scale goat producers in Wisconsin by providing them with the opportunity to direct-market locally raised and processed fresh Halal-slaughtered goat meat to the members of a growing Somali immigrant community in Northwestern Wisconsin and possibly to larger numbers of Somali immigrants living in the Minneapolis, MN, region. 


\section{USDA - Agricultural Marketing Service (AMS) \\ Federal State Marketing Improvement Program (FSMIP) \\ (View Program Description)}

\section{Alaska}

Project Type: Market Development

Year: 2004

Grantor: FSMIP

Grantee/Cooperator: Alaska Division of Agriculture

Grant Matching: 1 to 1

Funding: Grant $(\$ 46,000)$

Total: $\$ 92,000$

Objective: To expand the use of farmers markets as a direct marketing outlet for Alaskan growers.

\section{Illinois}

Project Type: Market Development

Year: 2003

Grantor: FSMIP

Grantee/Cooperator: Illinois Department of Agriculture

Grant Matching: 1 to 1

Funding: Grant $(\$ 72,650)$

Total: $\$ 145,300$

Objective: To determine the infrastructure and resources needed to support and maintain growth of an Illinois-based organic distribution system.

\section{Kentucky}

Project Type: Market Promotion

Year: 2004

Grantor: FSMIP

Grantee/Cooperator: Kentucky Department of Agriculture

Grant Matching: 1 to 1

Funding: Grant $(\$ 50,200)$

Total: $\$ 100,400$

Objective: To research consumer acceptance, pricing strategies, packaging options, handling needs and successful marketing approaches relating to non-traditional items such as aquaculture products and specialty meats sold through farmers markets to consumers and local restaurants.

\section{Massachusetts}

Project Type: Consumer Education and Access

Year: 2003

Grantor: FSMIP

Grantee/Cooperator: Massachusetts Department of Agriculture Resources

Grant Matching: 1 to 1

Funding: Grant $(\$ 51,100)$

Total: $\$ 102,200$

Objective: To foster direct marketing of locally-grown ethnic produce to Asian and Brazilian immigrant communities in Eastern Massachusetts. 


\section{$\underline{\text { Michigan }}$}

Project Type: Market Development

Year: 2006

Grantor: FSMIP

Grantee/Cooperator: Michigan Department of Agriculture / Michigan State University

Grant Matching: 1 to 1

Funding: Cooperative Agreement $(\$ 41,245)$

Total: $\$ 82,490$

Objective: To identify strategies for farmers markets managers, vendors, and public policy makers to increase the

number and diversity of customers at farmers markets in the state, with a focus on consumer groups that currently do not

shop at farmers markets.

Minnesota

Project Type: Producer Training and Support

Year: 2004

Grantor: FSMIP

Grantee/Cooperator: Minnesota Department of Agriculture

Grant Matching: 1 to 1

Funding: Grant $(\$ 12,000)$

Total: $\$ 24,000$

Objective: To address marketing challenges faced by immigrant growers who sell their products at urban farmers markets.

\section{(Back to table of contents)}




\section{USDA - Cooperative State Research, Education, and Extension Service (CSREES) Community Food Project \\ (View Program Description)}

\section{Arizona}

Project Type: Market Development

Year: 2004

Grantor: CSREES

Grantee/Cooperator: Natwanti Coalition, Hotevilla, AZ

Grant Matching: 1 to 1

Funding: Grant $(\$ 161,212)$

Total: $\$ 322,424$

Objective: To establish and staff a farmers market.

\section{California}

Project Type: Consumer Education and Access

Year: 2006

Grantor: CSREES

Grantee/Cooperator: Girls 2000, San Francisco, CA

Grant Matching: 1 to 1

Funding: Grant $(\$ 280,000)$

Total: $\$ 560,000$

Objective: To operate a weekly farmers' market in a high need area that will feature culturally-appropriate produce from minority-owned farms and youth-run, organic community gardens where the youth will also receive nutrition training and develop entrepreneurial skills for selling their products at the market.

Project Type: $\underline{\text { Market Development }}$

Year: 2006

Grantor: CSREES

Grantee/Cooperator: Thai Community Development Center, Los Angeles, CA

Grant Matching: 1 to 1

Funding: Grant $(\$ 20,000)$

Total: $\$ 40,000$

Objective: To develop a farmers' market in the Thai Town/East Hollywood area to provide access for local farmers and vendors to meet the demand for locally grown and produced foods for this multi-cultural and multi-ethnic community.

Project Type: Consumer Education and Access

Year: 2004

Grantor: CSREES

Grantee/Cooperator: Downtown El Cajon CDC, El Cajon, CA

Grant Matching: 1 to 1

Funding: Grant $(\$ 237,534)$

Total: $\$ 475,068$

Objective: To develop a year-round farmers market with nutrition education and cooking classes.

Project Type: Market Development

Year: 2003

Grantor: CSREES

Grantee/Cooperator: The Ecology Center, Berkley, CA

Grant Matching: 1 to 1

Funding: Grant $(\$ 200,000)$

Total: $\$ 400,000$

Objective: To distribute fresh produce at farmers markets. 
Project Type: Market Development

Year: 2003

Grantor: CSREES

Grantee/Cooperator: Environmental Science Institute, Oakland, CA

Grant Matching: 1 to 1

Funding: Grant $(\$ 225,000)$

Total: $\$ 450,000$

Objective: Market start-up and development of a farmers market association.

Project Type: Consumer Education and Access

Year: 2003

Grantor: CSREES

Grantee/Cooperator: Los Angeles Leadership Academy, Los Angeles, CA

Grant Matching: 1 to 1

Funding: Grant $(\$ 100,000)$

Total: $\$ 200,000$

Objective: To participate in transportation projects to farmers market.

\section{Georgia}

Project Type: Market Development

Year: 2003

Grantor: CSREES

Grantee/Cooperator: Rolling Hills RC\&D, Dallas, TX

Grant Matching: 1 to 1

Funding: Grant $(\$ 105,120)$

Total: $\$ 210,240$

Objective: Farmers market expansion.

\section{$\underline{\text { Indiana }}$}

Project Type: Consumer Education and Access

Year: 2006

Grantor: CSREES

Grantee/Cooperator: Mid North Food Pantry, Indianapolis, IN

Grant Matching: 1 to 1

Funding: Grant $(\$ 6,560)$

Total: $\$ 13,120$

Objective: To help empower emergency food pantry clients, this planning project will conduct a neighborhood food assessment, initiate a pilot program of composting and urban food production, and aid youth in selling food directly at a farmers' market.

\section{Massachusetts}

Project Type: Market Development

Year: 2004

Grantor: CSREES

Grantee/Cooperator: CISA, South Deerfield, MA

Grant Matching: 1 to 1

Funding: Grant $(\$ 125,000)$

Total: $\$ 250,000$

Objective: Farmers market expansion and enhancements. 


\section{Michigan}

Project Type: Consumer Education and Access

Year: 2006

Grantor: CSREES

Grantee/Cooperator: Allen Neighborhood Center, Lansing, MI

Grant Matching: 1 to 1

Funding: Grant $(\$ 240,000)$

Total: $\$ 480,000$

Objective: To initiate a greenhouse-based gardening program in a low-income urban neighborhood that will focus on youth gardening and greenhouse production, coupled with sales at a farmers' market and a mobile market for the delivery of food to shut-ins.

Nebraska

Project Type: Consumer Education and Access

Year: 2006

Grantor: CSREES

Grantee/Cooperator: Open Harvest Natural Foods Cooperative, Lincoln, NE

Grant Matching: 1 to 1

Funding: Grant $(\$ 275,982)$

Total: $\$ 551,964$

Objective: To address the food needs of different ethnic communities through a project advisory council, youth and community gardens, hands-on education in the food production cycle, culturally-appropriate instruction on food preparation, development of a farmers' market, and the translation of nutrition materials into other languages.

\section{New Mexico}

Project Type: Market Development

Year: 2005

Grantor: CSREES

Grantee/Cooperator: Pueblo de Pojoaque, Santa Fe, NM

Grant Matching: 1 to 1

Funding: Grant $(\$ 260,000)$

Total: $\$ 520,000$

Objective: To establish a Sunday outdoor farmers market with youth marketing.

\section{New York}

Project Type: Market Development

Year: 2006

Grantor: CSREES

Grantee/Cooperator: Broadway Market Management Corporation, Buffalo, NY

Grant Matching: 1 to 1

Funding: Grant $(\$ 25,000)$

Total: $\$ 50,000$

Objective: To strengthen an existing public market and fresh produce distribution center to help provide a comprehensive strategy for neighborhood re-development and the promotion of healthy food choices. 


\section{North Carolina}

Project Type: $\underline{\text { Consumer Education and Access }}$

Year: 2006

Grantor: CSREES

Grantee/Cooperator: Episcopal Diocese of North Carolina, Kinston, NC

Grant Matching: 1 to 1

Funding: Grant $(\$ 90,735)$

Total: $\$ 181,470$

Objective: To improve food security in a three-county area where an estimated 10,000 farm workers reside through community gardening; food preservation training; the construction and operation of a farmers' market and food exchange; and financial self-sufficiency training.

\section{Oregon}

Project Type: Market Development

Year: 2005

Grantor: CSREES

Grantee/Cooperator: Janus Youth Programs, Portland, OR

Grant Matching: 1 to 1

Funding: Grant $(\$ 270,000)$

Total: $\$ 540,000$

Objective: To establish monthly farmers market shuttle, cooking classes, and assessment of a mobile market.

\section{$\underline{\text { Tennessee }}$}

Project Type: Market Development

Year: 2004

Grantor: CSREES

Grantee/Cooperator: Rural Resources, Greenville, SC

Grant Matching: 1 to 1

Funding: Grant $(\$ 128,160)$

Total: $\$ 256,320$

Objective: To establish a mobile farmers market.

\section{Washington}

Project Type: Market Development

Year: 2006

Grantor: CSREES

Grantee/Cooperator: Cascade Land Conservancy, Seattle, WA

Grant Matching: 1 to 1

Funding: Grant $(\$ 25,000)$

Total: $\$ 50,000$

Objective: To conduct a feasibility study for the development of a cooperatively-run community supported agriculture (CSA) program managed through the local farmers' market.

\section{(Back to table of contents)}




\title{
USDA-Cooperative State Research, Education, and Extension Service (CSREES) Sustainable Agriculture Research and Education (SARE) (View Program Description)
}

\author{
New Hampshire
}

Project Type: Producer Training and Support

Year: 2004

Grantor: CSREES/SARE

Grantee/Cooperator: University of New Hampshire Cooperative Extension

Grant Matching: N/A

Funding: Grant $(\$ 30,968)$

Total: $\$ 30,968$

Objective: Market managers from 45 farmers markets in New Hampshire will be invited to attend a food stamp education workshop. Fifteen market managers will attend the workshop and 3 pilot markets will be recruited for this group. Market managers and farmers from the pilot markets will attend focus groups, food stamp trainings, debriefings and postintervention interviews to determine the success of the outcome of increasing revenues at the farmers markets by accepting food stamps.

\section{Six New England States}

Project Type: Producer Training and Support

Year: 2005

Grantor: CSREES/SARE

Grantee/Cooperator: Cooperative Development Institute

Grant Matching: N/A

Funding: Grant $(\$ 62,600)$

Total: $\$ 62,600$

Objective: This project will help strengthen the business skills of farmers participating in farmers markets. Training will focus on the business of farmers markets: board, staff and member roles and responsibilities; member retention and recruitment; equity assessment and fund raising; operational audits; advanced market and business planning; community alliances and the role of State farmers market associations in strengthening local markets. Resource providers will partner with a farmers market staff person to participate in the program. The program will advise teams that are making plans to strengthen local farmers markets. Training will be conducted in each of the six New England States. An advisory committee will help plan, publicize and conduct the trainings

\section{(Back to table of contents)}




\section{USDA - Food and Nutrition Service (FNS) \\ Food Stamp Program (FSP) \\ (View Program Description)}

\section{Arizona}

Project Type: Consumer Education and Access

Year: 2005

Grantor: FNS/FSP

Grantee/Cooperator: Farmers markets throughout the State

Grant Matching: N/A

Funding: Grant (N/A)

Total: N/A

Objective: Twelve farmers markets, many only open for part of the year, now accept Food Stamps. Most of these markets are now using wireless POS devices.

\section{California}

Project Type: Consumer Education and Access

Year: 2005

Grantor: FNS/FSP

Grantee/Cooperator: Farmers markets throughout the State

Grant Matching: N/A

Funding: Grant (N/A)

Total: N/A

Objective: The State is testing wireless POS devices and will allow them to be used at farmers markets and other nontraditional retailers. Currently, the State has deployed wireless POS devices to 26 individual FNS-authorized farmers that sell produce at the farmers markets with the highest historical food stamp redemption (Oakland, Richmond, Sacramento, San Francisco, and Stockton). In addition, 34 FNS authorized farmers markets throughout the State are using a wireless POS and a scrip solution, with 14 more soon to be added. The State is currently in the process of evaluating the wireless POS demonstration.

\section{Connecticut}

Project Type: $\underline{\text { Consumer Education and Access }}$

Year: 2005

Grantor: FNS/FSP

Grantee/Cooperator: Farmers Markets in Harford, New Haven, and Storrs

Grant Matching: N/A

Funding: Grant $(\$ 0)$

Total: $\$ 0$

Objective: Connecticut will have farmers markets in Hartford, New Haven, and Storrs using tokens to conduct EBT transactions. The markets will provide EBT access for food stamp recipients to purchase fresh produce and provide farmers with an additional source of revenue.

\section{Hawaii}

Project Type: Consumer Education and Access

Year: 2005

Grantor: FNS/FSP

Grantee/Cooperator: Hilo Farmers Markets

Grant Matching: N/A

Funding: Grant (N/A)

Total: N/A

Objective: Food stamp clients at The Hilo Farmers Market, which first started in 1998, use their EBT cards at a point of sale (POS) kiosk in the market, where the manager swipes the card and hands out scrip. The client then exchanges the scrip with individual vendors at the market for food. Refunds are also done at the POS. 
Illinois

Project Type: Consumer Education and Access

Year: 2003

Grantor: FNS/FSP

Grantee/Cooperator: Austin Farmers Market (Institute for Community Resource Development)

Grant Matching: N/A

Funding: Grant $(\$ 0)$

Total: $\$ 0$

Objective: Austin Farmers Market was set up by FNS in July 2002 as a farmers market/produce stand. The current demonstration project began the end of June 2003. Although several farmers markets in Chicago are authorized to accept food stamps, none of them—including Austin Farmers Market—have had a successful food stamp transaction since the project began.

\section{Kentucky}

Project Type: $\underline{\text { Consumer Education and Access }}$

Year: 2004

Grantor: FNS/FSP

Grantee/Cooperator: Portland Farmers Market

Grant Matching: N/A

Funding: Grant (\$0)

Total: $\$ 0$

Objective: The Portland Farmers Market project was approved for the 2004 growing season after the project was tested in 2003. The market will continue to use a token-based EBT system. The Portland Farmers Market is responsible for producing its own unique tokens according to State guidelines. The tokens are available for purchase in $\$ 1$ increments by Food Stamp households through the market manager's office or similar location, which is equipped with a wireless pointof-sale device for accepting EBT transactions.

Project Type: Consumer Education and Access

Year: 2003

Grantor: FNS/FSP

Grantee/Cooperator: Scott County Farmers Market

Grant Matching: N/A

Funding: Grant $(\$ 0)$

Total: $\$ 0$

Objective: The Scott County Farmers Market has been approved for a second growing season after beginning in 2003 . This market uses a voucher-based EBT system. EBT customers go to individual farmers and make their purchases. The farmer completes a voucher for the sale, which the customer then takes to the EBT POS terminal where the voucher amount is deducted from the customer's EBT account. The customer will then return to the farmer, provide a copy of the voucher showing proof of purchase, and obtain the food items.

\section{Louisiana}

Project Type: Market Development

Year: 2005

Grantor: FNS/FSP

Grantee/Cooperator: Crescent City Farmers Market

Grant Matching: N/A

Funding: Grant $(\$ 0)$

Total: $\$ 0$

Objective: The Crescent City Farmers Market in New Orleans is sponsored by Loyola University. The market operates in three different locations using wireless POS devices and tokens. 


\section{Massachusetts}

Project Type: Consumer Education and Access

Year: 2005

Grantor: FNS/FSP

Grantee/Cooperator: Lynn Farmers Market

Grant Matching: N/A

Funding: Grant $(\$ 0)$

Total: $\$ 0$

Objective: Lynn Farmers Market has been in operation since 1990. It is sponsored by the Food Project-North Shore. The market will begin a wireless, script-based demonstration project this summer. Food Project expects to purchase a wireless POS terminal and sell scrip to EBT customers in a pattern modeled after the Holyoke Farmers Market.

Project Type: Consumer Education and Access

Year: 2005

Grantor: FNS/FSP

Grantee/Cooperator: Holyoke Farmers Market

Grant Matching: N/A

Funding: Grant $(\$ 0)$

Total: $\$ 0$

Objective: Holyoke Farmers Market has a \$2 increments script-based EBT system in place operated by the Holyoke Chamber of Commerce.

Project Type: Consumer Education and Access

Year: 2005

Grantor: FNS/FSP

Grantee/Cooperator: Greater Worcester Farmers Market

Grant Matching: N/A

Funding: Grant $(\$ 0)$

Total: $\$ 0$

Objective: Greater Worcester uses a wireless POS device and a receipt-based system. Food stamp recipients choose items from individual vendors, then take the receipts to the market manager to purchase the items through the wireless POS system.

Project Type: Consumer Education and Access

Year: 2005

Grantor: FNS/FSP

Grantee/Cooperator: Farmers Market at the " $X$ " in Springfield

Grant Matching: N/A

Funding: Grant $(\$ 0)$

Total: $\$ 0$

Objective: Farmers and customers will use a central POS device to distribute scrip for purchases. The market is sponsored by the "X" Main Street Corporation.

Project Type: Consumer Education and Access

Year: 2005

Grantor: FNS/FSP

Grantee/Cooperator: Dudley Square Public market in Roxbury

Grant Matching: N/A

Funding: Grant $(\$ 0)$

Total: $\$ 0$

Objective: The market is sponsored by the Madison Park Development Corporation in partnership with the Food Project, Boston Public Health Commission, Nuestra Comunidad, Whittier Street Health Center, Haley House, and City Councilman Chuck Turner's office. It uses a wireless POS device and a receipt-based system, in which Food Stamp households choose eligible items from vendors. 
New Hampshire

Project Type: Consumer Education and Access

Year: 2004

Grantor: FNS/FSP

Grantee/Cooperator: University of New Hampshire Cooperative Extension Nutrition Connection Program and New

Hampshire Farmers Market Association

Grant Matching: N/A

Funding: Grant $(\$ 0)$

Total: $\$ 0$

Objective: The University of New Hampshire Cooperative Extension (UNHCE) Nutrition Connections Program, in collaboration with the New Hampshire Farmers Market Association, is assisting in the operation of a scrip-based farmers market project. The Farmers Market Association of Nashua, the Downtown Manchester Farmers Market and the Enfield Village Associate Farmers Market are participating in the program.

\section{New York}

Project Type: Consumer Education and Access

Year: 2004

Grantor: FNS/FSP

Grantee/Cooperator: New York Office of Temporary and Disability Assistance

Grant Matching: N/A

Funding: Grant $(\$ 100,000)$

Total: $\$ 100,000$

Objective: New York received another $\$ 100,000$ grant in the Appropriations Bill for wireless EBT at farmers markets. New York is redeploying the wireless terminals that were not used the previous year to other farmers who have shown interest, and is expanding the project to Syracuse. New York is also exploring the possibility of authorizing a market manager at smaller farmers markets to operate one central terminal, rather than authorizing the individual farmers. New York will continue outreach efforts to draw more Food Stamp recipients to the farmers markets.

Project Type: Consumer Education and Access

Year: 2003

Grantor: FNS/FSP

Grantee/Cooperator: New York State - New York Farmers Market Federation

Grant Matching: N/A

Funding: Grant (\$0)

Total: $\$ 0$

Objective: The New York Farmers Market Federation purchased 46 wireless terminals for use in farmers markets in Rochester, Buffalo, Niagara Falls and North Tonawanda. The terminals were purchased with $\$ 100,000$ in funds that the USDA Food \& Nutrition Service provided as part of the 2002 Federal Agricultural Appropriations Bill. Of the 46 terminals purchased, 27 were used, with total redemptions of $\$ 14,513$ from May through September.

\section{New Mexico}

Project Type: $\underline{\text { Consumer Education and Access }}$

Year: 2005

Grantor: FNS/FSP

Grantee/Cooperator: Taos Farmers Market Project

Grant Matching: N/A

Funding: Grant $(\$ 0)$

Total: $\$ 0$

Objective: At The Taos farmers market project, the purchaser takes a purchase receipt to a POS location adjacent to the market, where their EBT card is debited, then they return to the vendor to exchange the POS receipt for the purchased food. 


\section{Oregon}

Project Type: Consumer Education and Access

Year: 2005

Grantor: FNS/FSP

Grantee/Cooperator: Farmers markets throughout the State

Grant Matching: N/A

Funding: Grant (N/A)

Total: N/A

Objective: Five farmers markets in Oregon accept Food Stamps. All purchases go directly through the POS device, except the Eastbank Farmers Market, where tokens are used. The tokens are available for purchase by food stamp households through the market manager's office or similar location, which is equipped with a wireless point-of-sale device for accepting EBT transactions.

\section{Pennsylvania}

Project Type: Consumer Education and Access

Year: 2004

Grantor: FNS/FSP

Grantee/Cooperator: Commonwealth of Pennsylvania

Grant Matching: N/A

Funding: Grant $(\$ 0)$

Total: $\$ 0$

Objective: The Commonwealth of Pennsylvania began a demonstration project to ascertain the practicality, effectiveness, and cost efficiency of utilizing wireless POS technology for food stamp transactions when standard POS devices cannot be used. This project is in conjunction with two nonprofit organizations: The Food Trust in Philadelphia and Just Harvest in Pittsburgh. The Food Trust operates outdoor farmers markets in Philadelphia. Just Harvest gives technical assistance to several farmers who sell at farmers markets in Western Pennsylvania. As part of this project, all wireless POS device operating costs related to food stamp transactions are paid for by the Commonwealth. Some vendors in Pittsburgh also use the machines for commercial transactions, and pay for those operating costs themselves.

\section{South Carolina}

Project Type: Consumer Education and Access

Year: 2006

Grantor: FNS/FSP

Grantee/Cooperator: Farmers markets throughout the State

Grant Matching: N/A

Funding: Grant (N/A)

Total: N/A

Objective: The South Carolina Departments of Agriculture and Social Services will jointly sponsored 10 farmers markets throughout the State, using a token-based EBT alternative. The tokens are available for purchase by food stamp households through the market manager's office or similar location, which is equipped with a wireless point-of-sale device for accepting EBT transactions.

\section{Washington}

Project Type: Consumer Education and Access

Year: 2006

Grantor: FNS/FSP

Grantee/Cooperator: Farmers markets throughout the State

Grant Matching: N/A

Funding: Grant (N/A)

Total: N/A

Objective: Twelve farmers markets in Washington are authorized to operate EBT scrip systems: The Columbia City, University District, Lake City, and West Seattle Farmers Markets located in the Seattle area and the Olympia Farmers Market in Olympia are participating and redeeming FSP benefits. The Bellingham Farmers Market, San Juan Farmers Market, Magnolia Farmers Market, Pasco Farmers Market, and Pike Place are authorized but do not have redemptions this season. Other markets have expressed an interest in joining. The State is planning to offer wireless POS devices in the near future. 


\section{Wisconsin}

Project Type: Consumer Education and Access

Year: 2005

Grantor: FNS/FSP

Grantee/Cooperator: The Milwaukee Fondy Market

Grant Matching: N/A

Funding: Grant (\$0) Technical Assistance and Loans for EBT use

Total: $\$ 0$

Objective: A new Farmers Market opened in a highly populated food stamp recipient neighborhood in June 2005 . The Milwaukee Fondy Market provided technical assistance and is loaning the new market a wireless device for use by certified vendors.

$\underline{\text { Texas }}$

Project Type: Consumer Education and Access

Year: 2005

Grantor: FNS/FSP

Grantee/Cooperator: Texas Department of Agriculture

Grant Matching: N/A

Funding: Grant $(\$ 0)$

Total: $\$ 0$

Objective: Several pilot studies were conducted by the Texas Department of Agriculture, which oversees farmers markets in Texas, and the Texas Department of Human Services, Lone Star Technology (EBT), during the 2002 growing season to evaluate methods of using the Lone Star card in different types of markets. Markets included in the pilot program were Ridgmar Farmers Market, Del Rio Farmers Market, San Antonio Farmers Market/Tri-State Farmers Market, Lufkin Farmers Market, Jacksonville Farmers Market, and Eagle Pass Farmers Market.

\section{(Back to table of contents)}




\section{USDA - Food and Nutrition Service (FNS) \\ Farmers Market Nutrition Program (FMNP) (View Program Description)}

Women, Infants, and Children (WIC) Farmers Market Nutrition Program - The WIC Farmers Market Nutrition Program provides participants in the Special Supplemental Nutrition Program for WIC with coupons that can be exchanged for fresh fruits, vegetables and herbs at local farmers markets and roadside stands. Grants are made to State agencies, which authorize farmers, markets and/or roadside stands to accept the coupons. For the period of 2003-2005 FNS provided grants in the following amounts for each fiscal year:

- $\quad F Y$ 2003: $\$ 24,994,688$

- $\quad F Y 2004: \$ 27,951,989$

- FY 2005: $\$ 28,066,989$

- $\quad F Y 2006: \$ 23,809,901$

Senior Farmers Market Nutrition Program - The Senior Farmers Market Nutrition Program provides low-income seniors with coupons that can be exchanged for fresh fruits, vegetables and herbs at farmers markets, roadside stands, and community supported agriculture programs (CSAs). Grants are made to State agencies, which authorize farmers, markets, roadside stands, and CSAs to accept the coupons. For the period of 2003-2005 FNS provided grants in the following amounts for each fiscal year:

- $\quad F Y 2003: \$ 16,820,600$

- $\quad F Y$ 2004: $\$ 16,707,579$

- FY 2005: $\$ 15,000,000$

- FY 2006: $\$ 15,843,618$

Additional projects funded by FNS/FMNP:

\section{Arizona}

Project Type: Market Development

Year: 2005

Grantor: FNS-FMNP

Grantee/Cooperator: FMNP State Agency

Grant Matching: N/A

Funding: Grant $(\$ 6,067)$

Total: $\$ 6,067$

Objective: To publicize farmers markets in underserved areas.

Project Type: Market Development

Year: 2004

Grantor: FNS-FMNP

Grantee/Cooperator: FMNP State Agency

Grant Matching: N/A

Funding: Grant $(\$ 6,067)$

Total: $\$ 6,067$

Objective: To develop markets in Tribal communities and rural areas.

\section{Arkansas}

Project Type: Market Development

Year: 2004

Grantor: FNS-FMNP

Grantee/Cooperator: FMNP State Agency

Grant Matching: N/A

Funding: Grant $(\$ 4,900)$

Total: $\$ 4,900$

Objective: To assist 7 new applicants (Boone, Green, Johnson, Perry, Phillips, Randolph and Union counties) to develop markets. 


\section{California}

Project Type: Market Development

Year: 2005

Grantor: FNS-FMNP

Grantee/Cooperator: FMNP State Agency

Grant Matching: N/A

Funding: Grant $(\$ 30,978)$

Total: $\$ 30,978$

Objective: To develop new markets in underserved areas.

\section{District of Columbia}

Project Type: Market Development

Year: 2005

Grantor: FNS-FMNP

Grantee/Cooperator: FMNP State Agency

Grant Matching: N/A

Funding: Grant $(\$ 7,786)$

Total: $\$ 7,786$

Objective: To expand awareness and use of farmers markets in low-income sections of the city.

\section{Florida}

Project Type: Market Development

Year: 2005

Grantor: FNS-FMNP

Grantee/Cooperator: FMNP State Agency

Grant Matching: N/A

Funding: Grant $(\$ 7,731)$

Total: $\$ 7,731$

Objective: To develop farmers markets in rural, economically deprived counties.

\section{Guam}

Project Type: Market Development

Year: 2005

Grantor: FNS-FMNP

Grantee/Cooperator: FMNP State Agency

Grant Matching: N/A

Funding: Grant $(\$ 2,469)$

Total: $\$ 2,469$

Objective: To conduct educational outreach promotion to encourage more farmers to participate in the FMNP.

\section{Maryland}

Project Type: Market Development

Year: 2005

Grantor: FNS-FMNP

Grantee/Cooperator: FMNP State Agency

Grant Matching: N/A

Funding: Grant $(\$ 8,820)$

Total: $\$ 8,820$

Objective: To assist in establishing two new markets and relocating a third market in underserved areas. To establish new WIC clinics in Prince George's and Anne Arundel Counties. 


\section{Michigan}

Project Type: Market Development

Year: 2004

Grantor: FNS-FMNP

Grantee/Cooperator: FMNP State Agency

Grant Matching: N/A

Funding: Grant $(\$ 10,310)$

Total: $\$ 8,820$

Objective: To provide outreach to farmers in the metro Detroit area and encourage participation in the Eastern Market.

\section{New Hampshire}

Project Type: Market Development

Year: 2005

Grantor: FNS-FMNP

Grantee/Cooperator: New Hampshire Health Department - FMNP State Agency

Grant Matching: N/A

Funding: Grant $(\$ 2,781)$

Total: $\$ 2,781$

Objective: To expand markets in underserved areas in Plymouth, Berlin, Winchester, Derry, and Henniker.

\section{$\underline{\text { New Mexico }}$}

Project Type: Market Development

Year: 2005

Grantor: FNS-FMNP

Grantee/Cooperator: FMNP State Agency

Grant Matching: N/A

Funding: Grant $(\$ 7,858)$

Total: $\$ 7,858$

Objective: To assist newly-formed markets.

\section{New York}

Project Type: Market Development

Year: 2005

Grantor: FNS-FMNP

Grantee/Cooperator: New York Department of Agriculture and Markets-FMNP State Agency

Grant Matching: N/A

Funding: Grant $(\$ 89,048)$

Total: $\$ 89,048$

Objective: In conjunction with the Farmers Market Federation of New York, to conduct a series of 6 seminars to train market managers and recruit farmers for new and current markets.

\section{Pennsylvania}

Project Type: Market Development

Year: 2003

Grantor: FNS-FMNP

Grantee/Cooperator: Pennsylvania Department of Agriculture - FMNP State Agency

Grant Matching: N/A

Funding: Grant $(\$ 46,428)$

Total: $\$ 46,428$

Objective: To pay for newspaper ads to recruit farmers for Philadelphia and other urban areas and purchase signs, ads, etc. for farmers markets. 


\section{Women, Infants, and Children (WIC) Farmers Market Nutrition Program Grants:}

Alabama

Farmers Market Authority

FY 2003: $\$ 239,850$

FY 2004: \$506,666

FY 2005: \$506,666

FV 2006: $\$ 428,980$
Alaska

Maternal, Child \& Family Health

FY 2003: $\$ 290,029$

FY 2004: \$290,029

FY 2005: $\$ 290,029$

FV 2006: $\$ 245,559$

\section{Arizona}

Department of Health Services

FY 2003: $\$ 303,333$

FY 2004: $\$ 303,333$

FY 2005: $\$ 303,333$

FV 2006: \$256,824
Arkansas

Department of Health

FY 2003: $\$ 245,000$

FY 2004: $\$ 245,000$

FY 2005: $\$ 245,000$

FV 2006: \$207,434

\section{California}

Department of Health

FY 2003: \$3,097,875

FY 2004: $\$ 3,097,875$

FY 2005: $\$ 3,097,875$

FV 2006: $\$ 2,622,887$
Connecticut

Department of Agriculture

FY 2003: $\$ 409,879$

FY 2004: $\$ 409,879$

FY 2005: $\$ 409,879$

FV 2006: $\$ 347,033$
District of Columbia

Department of Health

FY 2003: \$389,276

FY 2004: \$389,276

FY 2005: $\$ 389,276$

FV 2006: $\$ 329,589$

\section{Florida}

Department of Agriculture \&

Consumer Services

FY 2003: \$366,543

FY 2004: \$366,543

FY 2005: \$366,543

FV 2006: $\$ 310,342$

\section{Georqia}

Department of Public Health

FY 2003: $\$ 809,243$

FY 2004: $\$ 1,309,243$

FY 2005: $\$ 1,309,243$

FV 2006: $\$ 1,102,499$
Guam

Department of Public Health \&

Social Services

FY 2003: $\$ 123,457$

FY 2004: $\$ 123,457$

FY 2005: \$123,457

FV 2006: $\$ 104,527$
Illinois

Department of Human Services

FY 2003: \$322,166

FY 2004: $\$ 500,000$

FY 2005: $\$ 500,000$

FV 2006: $\$ 423,337$

\section{Indiana}

Department of Health Services

FY 2003: \$284,696

FY 2004: $\$ 328,410$

FY 2005: $\$ 328,410$

FV 2006: $\$ 278,055$ lowa

Department of Agriculture \&

Land Stewardship'

FY 2003: \$641,320

FY 2004: \$641,320

FY 2005: $\$ 641,320$

FV 2006: \$542,988
Kentucky

Department of Agriculture

FY 2003: $\$ 230,000$

FY 2004: $\$ 290,000$

FY 2005: \$290,000

FV 2006: \$245,535

\section{Louisiana}

Department of Agriculture \& Forestry

FY 2003: $\$ 0$

FY 2004: $\$ 0$

FY 2005: \$6,667

FV 2006: \$6,667

*State agency declined to participate in FY 2003 and 2004.
Maine

Department of Human Services

FY 2003: $\$ 85,000$

FY 2004: $\$ 85,000$

FY 2005: $\$ 85,000$

FV 2006: $\$ 75,000$

\section{Maryland}

Department of Agriculture

FY 2003: $\$ 624,843$

FY 2004: $\$ 441,000$

FY 2005: $\$ 441,000$

FV 2006: \$373,382

*State agency requested less in FY 2004 than its FY 2003 grant.

\section{Massachusetts}

Department of Food \& Agriculture

FY 2003: $\$ 607,229$

FY 2004: $\$ 607,229$

FY 2005: $\$ 607,229$

FV 2006: $\$ 514,124$

\section{Michigan}

Department of Community Health

FY 2003: $\$ 515,490$

FY 2004: $\$ 515,490$

FY 2005: $\$ 515,490$

FV 2006: $\$ 436,452$

\section{Minnesota}

Department of Agriculture

FY 2003: \$396,667

FY 2004: \$396,667

FY 2005: \$396,667

FV 2006: \$335,847
Mississippi

Department of Agriculture

FY 2003: \$86,766

FY 2004: \$86,766

FY 2005: \$86,766

FV 2006: $\$ 75,000$ 
Mississippi

Band of Choctaws

FY 2003: $\$ 14,500$

FY 2004: $\$ 14,500$

FY 2005: $\$ 14,500$

FV 2006: $\$ 14,500$

\section{Missouri}

Department of Health \&

Senior Services

FY 2003: $\$ 257,137$

FY 2004: $\$ 257,137$

FY 2005: \$0

FV 2006: \$0

*State agency declined to participate

in FY 2005 and 2006.

\section{Montana}

Department of Public Health \&

Human Services

FY 2003: $\$ 70,000$

FY 2004: $\$ 57,353$

FY 2005: $\$ 57,353$

FV 2006: $\$ 57,353$

*State agency requested less in $\mathrm{FY}$ 2004 than its FY 2003 grant.
New Hampshire

Department of Health \&

Human Services

FY 2003: $\$ 139,047$

FY 2004: $\$ 139,047$

FY 2005: \$139,047

FV 2006: $\$ 117,727$
New Jersey

Department of Health \&

Senior Services

FY 2003: $\$ 1,586,411$

FY 2004: $\$ 1,586,411$

FY 2005: $\$ 1,586,411$

FV 2006: $\$ 1,343,170$
New Mexico

Department of Health

FY 2003: \$392,891

FY 2004: \$392,891

FY 2005: $\$ 392,891$

FV 2006: $\$ 332,650$
New Mexico

5 Sandoval Indian Pueblos, Inc.

FY 2003: $\$ 6,337$

FY 2004: \$6,337

FY 2005: \$6,337

FV 2006: \$6,337

\section{New Mexico}

Pueblo of San Felipe

FY 2003: $\$ 8,666$

FY 2004: $\$ 8,666$

FY 2005: $\$ 8,666$

FV 2006: $\$ 8,666$

\section{New York}

Department of Agriculture \& Markets FY 2003: $\$ 4,083,332$

FY 2004; $\$ 4,452,384$

FY 2005: $\$ 4,452,384$

FV 2006: $\$ 3,769,708$

\section{North Carolina}

Department of Health \&

Human Services

FY 2003: $\$ 365,470$

FY 2004: \$0

FY 2005: $\$ 365,470$

FV 2006: $\$ 309,433$

*State agency declined to participate

in FY 2004.

\section{Ohio}

Department of Health

FY 2003: \$393,964

FY 2004: $\$ 672,288$

FY 2005: $\$ 672,288$

FV 2006: $\$ 569,208$

\section{Oregon}

Department of Human Services

FY 2003: $\$ 386,400$

FY 2004: $\$ 472,500$

FY 2005: $\$ 472,500$

FV 2006: $\$ 400,053$

\section{Oklahoma}

Chickasaw Nation

FY 2003: $\$ 40,000$

FY 2004: $\$ 80,000$

FY 2005: $\$ 80,000$

FV 2006: $\$ 75,000$

\section{Oklahoma}

Osage Tribal Council

FY 2003: \$31,325

FY 2004: \$31,325

FY 2005: \$31,325

FV 2006: \$31,325
Pennsylvania

Department of Agriculture

FY 2003: \$2,312,386

FY 2004: \$2,312,386

FY 2005: \$2,312,386

FV 2006: $\$ 1,957,834$

\section{Puerto Rico}

Agriculture Services \&

Development Administration

FY 2003: \$1,534,641

FY 2004: \$2,333,613

FY 2005: \$2,333,613

FV 2006: $\$ 1,975,806$
Rhode Island

Department of Health

FY 2003: \$198,313

FY 2004: \$196,796

FY 2005: \$196,796

FV 2006: \$166,621

* State agency requested less in $\mathrm{FY}$

2004 than its FY 2003 grant.

\section{South Carolina}

Department of Health \&

Environmental Control

FY 2003: \$132,530

FY 2004: \$166,235

FY 2005: \$166,235

FV 2006: $\$ 140,747$ 
Tennessee

Department of Health

FY 2003: $\$ 96,000$

FY 2004: $\$ 96,000$

FY 2005: $\$ 96,000$

FV 2006: $\$ 81,000$
Department of Health

FY 2003: $\$ 1,650,000$

FY 2004: $\$ 1,650,000$

FY 2005: $\$ 1,650,000$

FV 2006: $\$ 1,397,010$
Department for Children \& Families

FY 2003: \$75,676

FY 2004: $\$ 75,676$

FY 2005: $\$ 75,676$

FV 2006: $\$ 75,000$
Virginia

Department of Health

FY 2003: -.-

FY 2004: $\$ 387,952$

FY 2005: $\$ 387,952$

FV 2006: $\$ 328,468$

*New State agency in FY 2004.
Washington

Department of Health

FY 2003: \$334,000

FY 2004: $\$ 760,000$

FY 2005: $\$ 760,000$

FV 2006: $\$ 643,471$
West Virginia

Department of Health \&

Human Services

FY 2003: $\$ 70,000$

FY 2004: $\$ 70,000$

FY 2005: $\$ 70,000$

FV 2006: $\$ 70,000$

\section{Wisconsin}

Department of Health \&

Family Services

FY 2003: $\$ 747,000$

FY 2004: $\$ 799,309$

FY 2005: \$799,309

FV 2006: $\$ 676,753$

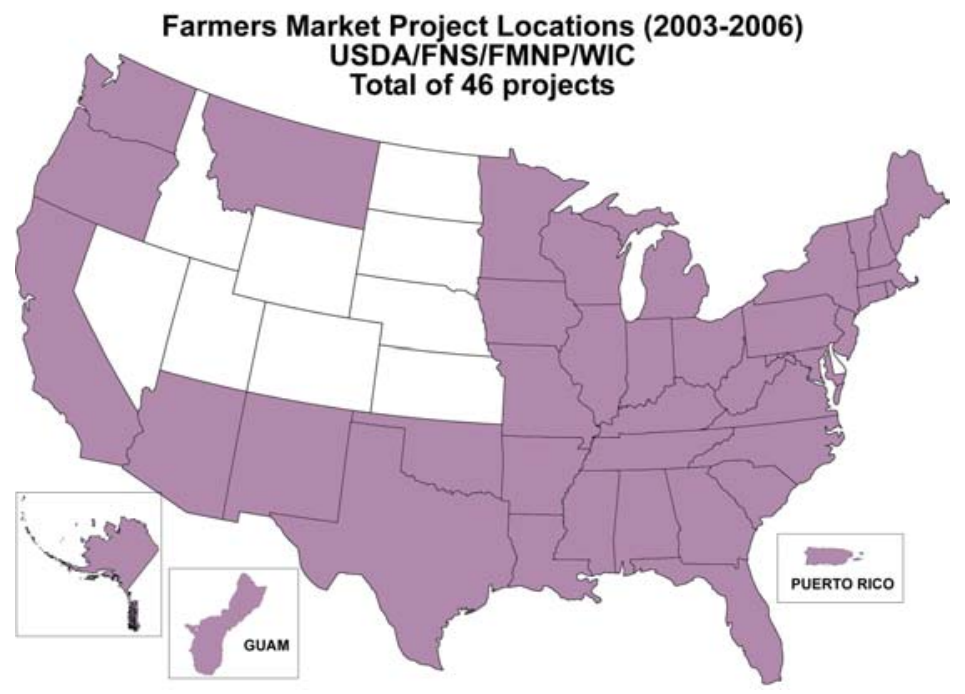




\section{Senior Farmers Market Nutrition Program (SFMNP) Grants:}

Alabama

Farmers Market Authority

FY 2003: $\$ 757,760$

FY 2004: $\$ 1,000,000$

FY 2005: $\$ 910,819$

FV 2006: \$962,045
Alaska

Department of Health \& Social

Services

FY 2003: $\$ 52,221$

FY 2004: \$70,498

FY 2005: $\$ 64,211$

FV 2006: $\$ 67,822$
Arkansas

Department of Human Services

FY 2003: $\$ 96,335$

FY 2004: $\$ 96,335$

FY 2005: $\$ 87,744$

FV 2006: \$92,679

\section{California}

Department of Aging

FY 2003: $\$ 791,800$

FY 2004: $\$ 673,430$

FY 2005: $\$ 613,373$

FV 2006: $\$ 647,870$

\section{Colorado}

Department of Agriculture

FY 2003: $\$ 0$

FY 2004: $\$ 15,000$

FY 2005: $\$ 13,662$

FV 2006: $\$ 14,430$

\section{Connecticut}

Department of Agriculture

FY 2003: \$91,148

FY 2004: $\$ 91,148$

FY 2005: $\$ 83,019$

FV 2006: $\$ 87,688$
District of Columbia

Department of Health

FY 2003: \$143,080

FY 2004: \$142,394

FY 2005: \$129,695

FV 2006: \$136,989
Florida

Department of Elder Affairs

FY 2003: \$96,604

FY 2004: \$96,576

FY 2005: \$87,964

FV 2006: $\$ 92,911$
Hawaii

Department of Labor \& Industrial

Relations

FY 2003: \$575,246

FY 2004: $\$ 575,246$

FY 2005: $\$ 523,945$

FV 2006: $\$ 553,412$

\section{Illinois}

Department of Human Services

FY 2003: \$814,362

FY 2004: $\$ 777,194$

FY 2005: $\$ 707,883$

FV 2006: $\$ 747,695$

\section{Indiana}

Department of Health

FY 2003: \$42,297

FY 2004: $\$ 40,437$

FY 2005: $\$ 36,831$

FV 2006: $\$ 38,902$

\section{lowa}

Department of Agriculture \&

Land Stewardship

FY 2003: \$467,997

FY 2004: $\$ 560,000$

FY 2005: $\$ 510,059$

FV 2006: $\$ 538,745$

\section{Kansas}

Department of Aging

FY 2003: \$182,439

FY 2004: \$196,020

FY 2005: $\$ 178,539$

FV 2006: $\$ 188,580$

\section{Kentucky}

Department of Agriculture

FY 2003: $\$ 750,000$

FY 2004: \$276,302

FY 2005: $\$ 251,661$

FV 2006: \$265,815

\section{Louisiana}

Department of Agriculture

\& Forestry

FY 2003: \$284,644

FY 2004: $\$ 279,584$

FY 2005: $\$ 254,650$

FV 2006: $\$ 268,972$

\section{Maine}

Department of Agriculture

FY 2003: \$893,220

FY 2004: \$892,925

FY 2005: \$813,294

FV 2006: \$859,035
Maryland

Department of Agriculture

FY 2003: \$130,988

FY 2004: \$114,607

FY 2005: $\$ 104,387$

FV 2006: \$110,258
Massachusetts

Department of Food \& Agriculture FY 2003: $\$ 56,900$

FY 2004: $\$ 56,900$

FY 2005: $\$ 51,826$

FV 2006: $\$ 54,741$

\section{Michigan}

Department of Community Health, Office of Services to Aging

FY 2003: $\$ 0$

FY 2004: $\$ 75,000$

FY 2005: $\$ 68,312$

FV 2006: $\$ 72,154$

\section{Michigan}

Grand Traverse Band of Ottawa \&

Chippewa Indians

FY 2003: $\$ 6,440$

FY 2004: $\$ 8,694$

FY 2005: $\$ 7,919$

FV 2006: $\$ 8,363$
Minnesota

Department of Agriculture

FY 2003: $\$ 77,280$

FY 2004: $\$ 99,776$

FY 2005: $\$ 90,878$

FV 2006: $\$ 95,989$ 
Mississippi

Band of Choctaw Indians

FY 2003: \$0

FY 2004: $\$ 15,215$

FY 2005: $\$ 13,858$

FV 2006: \$14,637
Mississippi

Department of Agriculture

FY 2003: \$0

FY 2004: $\$ 70,000$

FY 2005: $\$ 63,758$

FV 2006: $\$ 67,344$
Missouri

Department of Health

FY 2003: \$238,888

FY 2004: $\$ 238,888$

FY 2005: \$0

FV 2006: \$0
Montana

Department of Public Health \&

Human Services

FY 2003: $\$ 43,313$

FY 2004: $\$ 43,313$

FY 2005: $\$ 39,450$

FV 2006: $\$ 41,669$
Nebraska

Department of Agriculture

FY 2003: \$205,885

FY 2004: \$251,127

FY 2005: $\$ 228,731$

FV 2006: \$241,595

\section{Nevada}

Department of Administration

FY 2003: \$200,010

FY 2004: \$141,579

FY 2005: \$128,953

FV 2006: \$136,205
New Hampshire

Department of Health \&

Human Services

FY 2003: $\$ 86,00$

FY 2004: $\$ 75,744$

FY 2005: \$98,989

FV 2006: $\$ 72,869$

\section{New Jersey}

Department of Health \&

Senior Services

FY 2003: $\$ 560,734$

FY 2004: $\$ 683,109$

FY 2005: $\$ 622,189$

FV 2006: \$657,182
New Mexico

Pueblo of San Felipe

FY 2003: \$0

FY 2004: $\$ 16,560$

FY 2005: $\$ 15,084$

FV 2006: \$15,932
New Mexico

5 Sandoval Indian Pueblos, Inc.

FY 2003: $\$ 0$

FY 2004: $\$ 20,000$

FY 2005: $\$ 18,216$

FV 2006: $\$ 19,240$
New York

Department of Agriculture \& Markets

FY 2003: $\$ 1,499,059$

FY 2004: $\$ 1,499,059$

FY 2005: $\$ 1,365,368$

FV 2006: \$1,442,159
North Carolina

Department of Health \& Human Services

FY 2003: $\$ 54,000$

FY 2004: $\$ 44,263$

FY 2005: $\$ 40,315$

FV 2006: $\$ 42,582$

\section{Ohio}

Department of Aging

FY 2003: \$1,309,052

FY 2004: \$1,309,052

FY 2005: \$1,192,310

FV 2006: $\$ 1,259,367$

\section{Oregon}

Department of Human Services

FY 2003: \$882,249

FY 2004: \$772,175

FY 2005: $\$ 703,311$

FV 2006: $\$ 742,866$

\section{Oklahoma}

Chickasaw Nation of Oklahoma

FY 2003: \$144,845

FY 2004: $\$ 144,845$

FY 2005: $\$ 131,927$

FV 2006: \$139,347

\section{Oklahoma}

Osage Tribal Council

FY 2003: \$22,270

FY 2004: $\$ 30,672$

FY 2005: \$27,936

FV 2006: \$29,507
Pennsylvania

Department of Agriculture

FY 2003: $\$ 1,500,000$

FY 2004: $\$ 1,500,000$

FY 2005: $\$ 1,366,229$

FV 2006: $\$ 1,443,068$
Puerto Rico

Department of Agriculture FY 2003: $\$ 1,000,000$

FY 2004: $\$ 940,681$

FY 2005: \$856,791

FV 2006: $\$ 904,978$

\section{Rhode Island}

Division of Agriculture

FY 2003: $\$ 0$

FY 2004: \$198,561

FY 2005: \$180,844

FV 2006: \$191,015

South Carolina
Department of Social Services
FY 2003: $\$ 570,925$
FY 2004: $\$ 650,000$
FY 2005: $\$ 592,032$
FV 2006: $\$ 625,329$

\section{Tennessee}

Department of Health

FY 2003: $\$ 472,980$

FY 2004: $\$ 504,630$

FY 2005: \$459,627

FV 2006: \$485,477 


\section{Vermont}

Department of Aging \&

Independent Living

FY 2003: $\$ 64,660$

FY 2004: \$87,291

FY 2005: $\$ 79,507$

FV 2006: $\$ 83,979$

\section{Virginia}

Department of Aging

FY 2003: $\$ 493,707$

FY 2004: \$421,642

FY 2005: $\$ 384,040$

FV 2006: \$405,639

\section{Washington}

Department of Social \&

Health Services

FY 2003: $\$ 123,720$

FY 2004: $\$ 123,720$

FY 2005: \$112,686

FV 2006: \$119,024
West Virginia

Department of Agriculture

FY 2003: \$737,973

FY 2004: \$514,144

FY 2005: $\$ 468,293$

FV 2006: $\$ 494,630$

\section{Wisconsin}

Department of Agriculture Trade

\& Consumer Protection

FY 2003: \$299,579

FY 2004: \$273,254

FY 2005: $\$ 248,885$

FV 2006: $\$ 262,883$

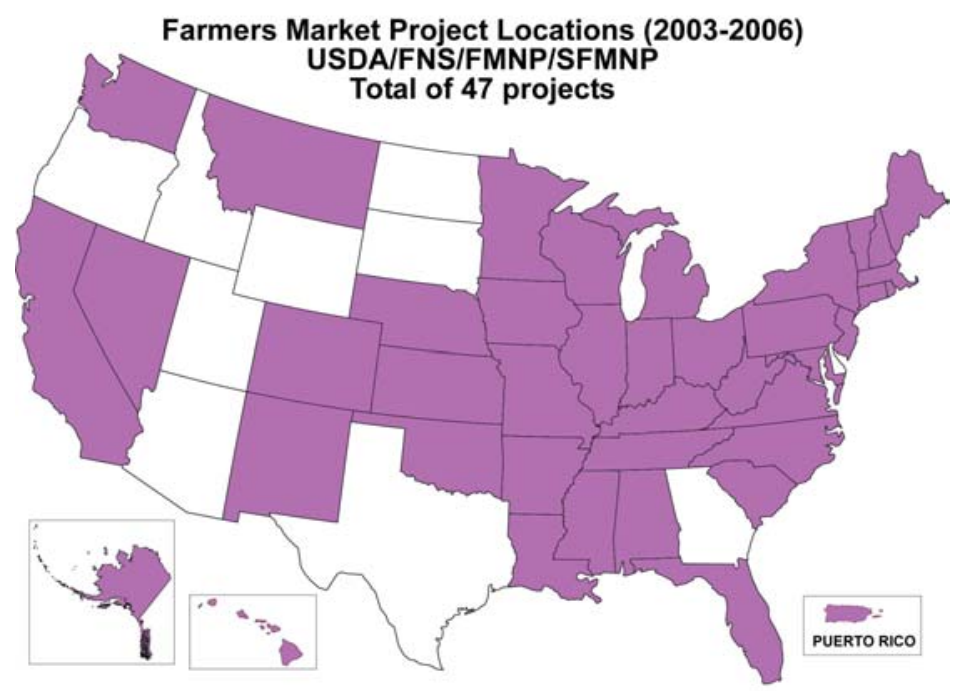

(Back to table of contents) 


\section{USDA-National Resource Conservation Service (NRCS) Resource Conservation \& Development Program (RC\&D) (View Program Description)}

\section{Alabama}

Project Type: Market Development

Year: 2004

Grantor: NRCS/Mid-South RC\&D Council

Grantee/Cooperator: Montgomery Farmers Market

Grant Matching: N/A

Funding: Technical Assistance

Total: N/A

Objective: Established a farmers market in Montgomery, Alabama.

Project Type: Market Development

Year: 2004

Grantor: NRCS/ALA-TOM RC\&D Council

Grantee/Cooperator: Alabama Farmers Market Authority

Grant Matching: N/A

Funding: Technical Assistance

Total: N/A

Objective: To establish two farmers markets. One was completed in 2005 and one in spring 2006.

Project Type: Market Development

Year: 2006

Grantor: NRCS/ Tombigbee RC\&D Council

Grantee/Cooperator: Green/Sumter Farmers Market

Grant Matching: N/A

Funding: Technical Assistance

Total: N/A

Objective: Install storage facilities, cold storage and restrooms at the Green/Sumter Farmers Market

\section{Arkansas}

Project Type: Market Development

Year: 2006

Grantor: NRCS/ Ozark Foothills RC\&D Council

Grantee/Cooperator:

Grant Matching: N/A

Funding: Technical Assistance

Total: N/A

Objective: Conducted a survey of existing Farmers Markets in the Council Area, including facility specifications.

\section{Idaho}

Project Type: $\underline{\text { Market Development }}$

Year: 2007

Grantor: NRCS/ Clearwater RC\&D Council

Grantee/Cooperator:

Grant Matching: N/A

Funding: Technical Assistance

Total: N/A

Objective: Developing an internet virtual farmers market to be utilized by producers in north central Idaho. 
Indiana

Project Type: Market Development

Year: 2005

Grantor: NRCS/ White River RC\&D Council

Grantee/Cooperator: Orange County

Grant Matching: N/A

Funding: Technical Assistance

Total: N/A

Objective: Develop a new Farmers Market.

\section{Kentucky}

Project Type: Market Development

Year: 2005

Grantor: NRCS/ Thoroughbred RC\&D Council

Grantee/Cooperator: Friends of the Lexington Farmers Market

Grant Matching: N/A

Funding: Technical Assistance

Total: N/A

Objective: Serve as the Fiscal Agent for the Friends of the Lexington Farmers Market.

\section{Louisiana}

Project Type: Market Development

Year: 2005

Grantor: NRCS/Bayou Land RC\&D Council

Grantee/Cooperator: German Coast Farmers Market, St. Charles Parish

Grant Matching: N/A

Funding: Technical Assistance

Total: N/A

Objective: Helped to development by-laws, guidelines, and a 501 establishment.

\section{Massachusetts}

Project Type: Market Development

Year: 2006

Grantor: NRCS/ Pilgrim Area RC\&D Council

Grantee/Cooperator: Carver Agricultural Commission

Grant Matching: N/A

Funding: Technical Assistance

Total: N/A

Objective: Assist the Carver Agricultural Commission and Planning department - NESARE Sustainable Communities grant writing and organizational assistance for starting and advancing farmers Market Promotion and connecting Carver residents with Community service and encouraging small local grower diversification.

\section{$\underline{\text { Tennessee }}$}

Project Type: Market Development

Year: 2005

Grantor: Hull-York RC\&D Council

Grantee/Cooperator: Hull-York Rural Development

Grant Matching: $\$ 125,000$

Funding: $\$ 40,000$

Total: $\$ 165,000$

Objective: Helped several farmers establish a new farmers market. Rural Development provided primary funding for the market, with the Rural Business Enterprise Grant contributing \$40,000 in 2005. 
Project Type: Market Development

Year: 2006

Grantor: Five Rivers RC\&D Council

Grantee/Cooperator: Humphreys Farmers Market

Grant Matching: N/A

Funding: Technical Assistance

Total: $\$$

Objective: Assisted with establishment a new farmers market. Rural Development provided primary funding for the market.

$\underline{\text { Utah }}$

Project Type: Market Development

Year: 2005

Grantor: Dinosaurland RC\&D Council

Grantee/Cooperator: Local Agricultural Producers

Grant Matching: N/A

Funding: Technical Assistance

Total: $\$$

Objective: Assisted with establishment a website in order to let public know where various local crops are available for purchase.

Project Type: Market Development

Year: 2005

Grantor: Uinta Headwaters RC\&D Council

Grantee/Cooperator: Heber Valley Farmers Market

Grant Matching: N/A

Funding: Technical Assistance

Total: \$

Objective: Assisted with establishment and support for the Heber Valley Farmers Market. Allowing local farmers to sell products; local artisans sell products they make.

\section{Washington}

Project Type: Market Development

Year: 2004

Grantor: NRCS/South Central RC\&D Council

Grantee/Cooperator: Yakima Farmers Market

Grant Matching: N/A

Funding: Technical Assistance

Total: N/A

Objective: Helped form the Yakima Farmers Market by assisting with the development of by-law, market guidelines, and 501 application and by serving in an advisory capacity for the first three years. The key to developing this successful market was hiring a consultant to develop initial market contacts and vendor requirements. The consultant and market startup expenses were paid with funding obtained through a Downtown Revitalization Group and tracked with City processes until the market was able to generate its own financial base.

Project Type: Market Development

Year: 2007

Grantor: North Central RC\&D Council \& WSDA

Grantee/Cooperator: Wenatchee Farmers Market

Grant Matching: N/A

Funding: Technical Assistance/ Personnel Salary

Total: $\$ 60,000$

Objective: Working with an EDD Regional Project Selection Committee, RC\&D staff and council members, and a Grant writing firm, applied for and received dollars to hire a staff person for the Wenatchee Farmers Market. 
West Virginia

Project Type: Market Development

Year: 2007

Grantor: Wes-Mon-Ty RC\&D Council

Grantee/Cooperator: Local Agricultural Producers

Grant Matching: N/A

Funding: Technical Assistance

Total: \$

Objective: Provide assistance to local sponsors in the development of Farmers Markets.

Wyoming

Project Type: Market Development

Year: 2007

Grantor: Western RC\&D Council

Grantee/Cooperator: Rock Springs Farmers Market

Grant Matching: N/A

Funding: Technical Assistance

Total: \$

Objective: Provide assistance for the development of Farmers Market.

(Back to table of contents) 


\section{USDA - Risk Management Agency (RMA) \\ Outreach Partnership Agreements \\ (View Program Description)}

\section{Arkansas}

Project Type: Producer Training and Support

Year: 2005

Grantor: RMA

Grantee/Cooperator: Risk Management Education for Limited Resource farmers, University of Arkansas, Pine Bluff,

School of Agriculture

Grant Matching: N/A

Funding: $(\$ 36,964)$

Total: $\$ 36,964$

Objective: To develop a risk management education program that meets the needs of Hispanic agricultural producers in Arkansas and Oklahoma.

\section{California}

Project Type: Producer Training and Support

Year: 2005

Grantor: RMA

Grantee/Cooperator: Hmong American Community

Grant Matching: N/A

Funding: $(\$ 66,556)$

Total: $\$ 66,556$

Objective: To address the technical, financial and marketing problems encountered by Hmong and Southeast Asian farmers in Fresno and Merced counties.

Project Type: Producer Training and Support

Year: 2005

Grantor: RMA

Grantee/Cooperator: Mandela Market Place, Inc.

Grant Matching: N/A

Funding: $(\$ 50,000)$

Total: $\$ 50,000$

Objective: To established a produce distribution business that brings together limited resource producers to supply inner-city markets.

Project Type: Producer Training and Support

Year: 2005

Grantor: RMA

Grantee/Cooperator: Risk Management Outreach and Technical Assistance for Limited Resource Immigrant Farmers, Opening Doors, Inc.

Grant Matching: N/A

Funding: $(\$ 100,000)$

Total: $\$ 100,000$

Objective: To provide risk management training and assistance to limited resource and traditionally underserved farmers on record keeping, marketing and merchandizing and California Regulatory Compliance.

\section{Florida}

Project Type: Producer Training and Support

Year: 2005

Grantor: RMA

Grantee/Cooperator: Agricultural Risk Management Training and Outreach: To Small Farmers, North South Institute

Grant Matching: N/A

Funding: $(\$ 97,900)$

Total: $\$ 97,900$

Objective: To provide outreach and technical assistance based on successful models to assist 133 family farmers to mitigate the farm related risk of production, marketing, labor, financial and legal. 
$\underline{\text { Hawaii }}$

Project Type: Producer Training and Support

Year: 2005

Grantor: RMA

Grantee/Cooperator: Risk Management Training Program for Socially Disadvantaged Filipino \& Other Southeast Asian

Growers, University of Hawaii

Grant Matching: N/A

Funding: $(\$ 131,321)$

Total: $\$ 131,321$

Objective: To provide information and training on crop production, integrated pest management and pesticide safety, marketing, bookkeeping and farm finances to Filipino and other Southeast Asian producers.

\section{Massachusetts}

Project Type: Producer Training and Support

Year: 2005

Grantor: RMA

Grantee/Cooperator: Community Involved in Sustainable Agriculture (CISA)

Grant Matching: N/A

Funding: $(\$ 75,000)$

Total: $\$ 75,000$

Objective: To create a comprehensive risk management education and research program for women farmers who are selling direct to customers, building on programming initiated in 2004-2005.

\section{Minnesota}

Project Type: Producer Training and Support

Year: 2005

Grantor: RMA

Grantee/Cooperator: Risk Management Training and Technical Assistance to Minnesota's New Immigrant Farmers,

Minnesota Food Association

Grant Matching: N/A

Funding: $(\$ 95,900)$

Total: $\$ 95,900$

Objective: To provide outreach, risk management training and technical assistance to Southeast Asian/Hmong and Latino/Hispanic new immigrant farmers selling produce at farmers markets.

Project Type: Producer Training and Support

Year: 2005

Grantor: RMA

Grantee/Cooperator: Bringing Risk Management Tools to Organic and Sustainable Farms, Midwest Organic and Sustainable Education

Grant Matching: N/A

Funding: $(\$ 115,000)$

Total: $\$ 115,000$

Objective: To provide information about farm management, production and market diversification and other risk management methods to women, limited resource, socially disadvantaged and other traditionally underserved producers.

\section{Missouri}

Project Type: Producer Training and Support

Year: 2006

Grantor: RMA

Grantee/Cooperator: Winrock International

Grant Matching: N/A

Funding: $(\$ 175,000)$

Total: $\$ 175,000$

Objective: To create a multi-faceted approach to risk mitigation that will train key staff at organizations that support underserved farmers and farmers markets to train and conduct outreach with underserved farmers on improving direct marketing techniques and market managers on how to recruit underserved farmers.

\section{Oklahoma}


Project Type: Producer Training and Support

Year: 2005

Grantor: RMA

Grantee/Cooperator: Langston University

Grant Matching: N/A

Funding: $(\$ 215,000)$

Total: $\$ 215,000$

Objective: To train farmers to develop markets, establish marketing contracts, and keep records, and to provide information on the availability and use of risk management tools, programs and services.

\section{Oregon}

Project Type: Producer Training and Support

Year: 2005

Grantor: RMA

Grantee/Cooperator: Risk Management Education for Women and Limited Resource Farmers in Coastal Oregon, Shore Bank Enterprises

Grant Matching: N/A

Funding: $(\$ 82,280)$

Total: $\$ 82,280$

Objective: To train 125 limited resource farmers on the Oregon coast in business management, farm transfer/succession, and direct marketing.

\section{$\underline{\text { Texas }}$}

Project Type: Producer Training and Support

Year: 2005

Grantor: RMA

Grantee/Cooperator: Sustainable Food Center

Grant Matching: N/A

Funding: $(\$ 50,000)$

Total: $\$ 50,000$

Objective: To assist limited resource farmers in Central Texas, which includes Hispanic, female and other traditionally underserved farmers, to manage risks associated with direct marketing.

\section{Virginia}

Project Type: Producer Training and Support

Year: 2006

Grantor: RMA

Grantee/Cooperator: Risk Management Commodity Partnerships

Grant Matching: N/A

Funding: $(\$ 150,000)$

Total: $\$ 150,000$

Objective: To offer more than 60 risk management education workshops, demos, and meetings that will target fruit and vegetable-growers, direct marketers, farmers market groups, Christmas tree growers, livestock producers, and those interested in organic grain/equine feeds. Promote AGR-Lite awareness at all meetings.

\section{$\underline{\text { Wisconsin }}$}

Project Type: Producer Training and Support

Year: 2005 
Grantor: RMA

Grantee/Cooperator: Hydroponics Enterprise Education and Training, Micofarm Sustainable Research and Education

Grant Matching: N/A

Funding: $(\$ 60,000)$

Total: $\$ 60,000$

Objective: To provide information and training in hydroponics, marketing business, financial management, and other risk management tools.

\section{(Back to table of contents)}




\section{USDA - Rural Development (RD) Rural Business Programs (RBS) (View Program Description)}

\section{Alaska}

Project Type: Producer Training and Support

Year: 2003

Grantor: RBS

Grantee/Cooperator: Alaska Investnet

Grant Matching: N/A

Funding: $(\$ 65,400)$

Total: $\$ 65,400$

Objective: To provide technical assistance in entrepreneurial education.

\section{North Carolina}

Project Type: Producer Training and Support

Year: 2005

Grantor: RBS

Grantee/Cooperator: Jackson county

Grant Matching: N/A

Funding: $(\$ 80,000)$

Total: $\$ 80,000$

Objective: To assist with equipment purchase.

\section{South Dakota}

Project Type: Producer Training and Support

Year: 2004

Grantor: RBS

Grantee/Cooperator: Badlands SCEF

Grant Matching: N/A

Funding: $(\$ 42,000)$

Total: $\$ 42,000$

Objective: To provide technical assistance.

Project Type: Producer Training and Support

Year: 2004

Grantor: RBS

Grantee/Cooperator: Four Bands Community Fund, Inc.

Grant Matching: N/A

Funding: $(\$ 60,000)$

Total: $\$ 60,000$

Objective: To provide technical assistance and capitalization to a revolving loan fund.

Project Type: Producer Training and Support

Year: 2005

Grantor: RBS

Grantee/Cooperator: Murdo Development Corporation

Grant Matching: N/A

Funding: $(\$ 99,000)$

Total: $\$ 99,000$

Objective: To provide capitalization for a revolving loan fund. 
Project Type: Producer Training and Support

Year: 2005

Grantor: RBS

Grantee/Cooperator: Four Bands Community Fund, Inc.

Grant Matching: N/A

Funding: $(\$ 55,000)$

Total: $\$ 55,000$

Objective: To provide technical assistance and capitalization for a revolving loan fund.

Project Type: Producer Training and Support

Year: 2005

Grantor: RBS

Grantee/Cooperator: Lower Brule Sioux Tribe

Grant Matching: N/A

Funding: $(\$ 99,800)$

Total: $\$ 99,800$

Objective: To provide technical assistance and funds to renovate a building.

\section{(Back to table of contents)}




\section{Health and Human Services (HHS) \\ Office of Community Services (OCS) \\ (View Program Description)}

\section{Arizona}

Project Type: Producer Training and Support

Year: 2007

Grantor: DHHS - ORR

Grantee/Cooperator: International Rescue Committee of Phoenix

Funding: $\$ 118,750$

Match: N/A

Total: $\$ 118,750$

Objective: Use of 3-acre tract for training in production, business development instruction and creating market options, particularly in farmers markets and under a CSA.

\section{California}

Project Type: Consumer Education and Access

Year: 2007

Grantor: HHS - ORR

Grantee/Cooperator: International Rescue Committee of San Diego

Grant Matching: N/A

Funding: $\$ 64,799$

Total: $\$ 64,799$

Objective: Urban initiative for the establishment of an urban garden, educational school garden, farm to school sales, consumer education, improve community food security, and planning for the establishment of a farmers market.

Project Type: Consumer Education and Access

Year: 2006

Grantor: DHHS-ORR

Grantee/Cooperator: Fresno County Economic Opportunity Commission/Metro Ministries

Grant Matching: N/A

Funding: $(\$ 40,000)$

Total: $\$ 40,000$

Objective: As part of a broad approach to assist refugee farmers in Fresno and Merced Counties, arrangements were made to establish EBT terminals in two farmers markets and a flea market that permitted the purchase of fresh produce by Food Stamps recipients.

Project Type: Market Development

Year: 2005

Grantor: HHS - OCS

Grantee/Cooperator: Unity Council of Oakland

Grant Matching: N/A

Funding: $(\$ 200,000)$

Total: $\$ 200,000$

Objective: To develop a public/farmers market in a new mixed-use development at a major transit hub and provide access to local fresh food to the low-income Fruitvale. (OCS funding for FY 05 amounts to $\$ 250,000$.)

Project Type: Market Development

Year: 2005

Grantor: HHS - OCS

Grantee/Cooperator: Valley Economic Development Center, Panorama City

Grant Matching: N/A

Funding: $(\$ 200,000)$

Total: $\$ 200,000$

Objective: To sponsor a business entrepreneurship training program to assist low-income vendors to start and run successful businesses in an existing Mercado created from a failed strip mall, and plan "place-making" activities for the plaza such as screening of outdoor movies, cultural festivals, and a farmers market. 
Idaho

Project Type: Producer Training and Support

Year: 2007

Grantor: DHHS - ORR

Grantee/Cooperator: Mountain States Group Inc. in Boise

Funding: $\$ 101,194$

Match: N/A

Total: $\$ 101,184$

Objective: Use of community gardens for training in commercial growing and preparation as independent farmers, assistance in locating and acquiring land, and increasing awareness of farmers markets and other marketing opportunities.

\section{$\underline{\text { Kansas }}$}

Project Type: Producer Training and Support

Year: 2007

Grantor: DHHS - ORR

Grantee/Cooperator: Catholic Social Services of Kansas City

Funding: $\$ 106,999$

Grant Matching: N/A

Total: $\$ 106,999$

Objective: Incubator farm project incorporating training and technical assistance in organic crop production, record keeping, business management, equipment use and marketing.

\section{Kentucky}

Project Type: Producer Training and Support

Year: 2007

Grantor: DHHS-ORR

Grantee/Cooperator: Catholic Charities of Louisville

Funding: $\$ 95,584$

Grant Matching: N/A

Total: $\$ 95,584$

Objective: Urban project for African refugees combining a community garden and technical assistance with training in business development and direct marketing.

\section{Massachusetts}

Project Type: Producer Training and Support

Year: 2007

Grantor: HHS - ORR

Grantee/Cooperator: Massachusetts Office for Refugees and Immigrants

Grant Matching: N/A

Funding: $\$ 93,518$

Total: $\$ 93,518$

Objective: Use partnerships to develop new community gardens and farming opportunities, access to land, financing and resources, and training on marketing opportunities including farmers markets. 
New Hampshire

Project Type: Producer Training and Support

Year: 2007

Grantor: DHHS - ORR

Grantee/Cooperator: International Institute of New Hampshire

Funding: $\$ 80,072$

Grant Matching: N/A

Total: $\$ 80,072$

Objective: With the use of a training site program, provide instruction and technical assistance in production and

financial literacy, and the facilitation of market access and sales training for farmers markets and other sales outlets.

\section{North Carolina}

Project Type: Producer Training and Support

Year: 2007

Grantor: DHHS-ORR

Grantee/Cooperator: United Hmong Association of North Carolina

Grant Matching: N/A

Funding: $\$ 102,360$ :

Total: $\$ 102,360$

Objective: Training, mentoring and technical assistance for Hmong farmers on accessing land, production and selling at a farmers market.

\section{Oregon}

Project Type: Producer Training and Support

Year: 2007

Granter: DHHS-ORR

Grantee/Cooperator: Mercy Corps Northwest

Funding: $\$ 41,667$

Grant Matching: N/A

Total: $\$ 41,667$

Objective: Use of partnerships to incubate economically sustainable, small scale farm enterprises by focusing on direct marketing connections and education, land acquisition, access to capital and farm assets, business development training and services, and agricultural risk management education.

Project Type: Producer Training and Support

Year: 2006

Granter: DHHS-ORR

Grantee/Cooperator: Mercy Corps Northwest

Funding: $(\$ 20,000)$

Grant Matching: N/A

Other: $\$ 50,000$ from USDA Risk Management

Total: $\$ 70,000$

Objective: As part of a broad strategy to assist refugee farmers, four (4) Mesketian Turk extended families in the first year of production established a selling booth for organic vegetables in a farmers market and an after church farmers market in a local congregation. 


\section{Vermont}

Project Type: Producer Training and Support

Year: 2007

Grantor: DHHS - ORR

Grantee/Cooperator: Association of Africans Living in Vermont

Funding: $\$ 94,957$

Grant Matching: N/A

Total: $\$ 94,957$

Objective: Provide training and technical assistance through the use of an incubator farm and classroom instruction in production, business planning and marketing strategies, particularly in farmers markets.

\section{$\underline{\text { Wisconsin }}$}

Project Type: Producer Training and Support

Year: 2006

Grantor: DHHS-ORR

Grantee/Cooperator: Western Dairyland Economic Opportunity Council Inc. and Collaborators

Funding: $(\$ 15,000)$

Grant Matching: N/A

Other: $\$ 39,241$ from USDA Risk Management and $\$ 32,000$ from the University of Wisconsin Extension

Total: $\$ 86,241$

Objective: As part of a comprehensive strategy to assist Hmong farmers, the project assisted in locating new farmers' markets and a produce auction, and the development of a Hmong Foods Cookbook and recipe cards for use as marketing tools.

\section{(Back to table of contents)}




\title{
Private Sector and Foundation Farmers Market Projects
}

\author{
Project for Public Spaces \\ Funding Provided by the Ford Foundation \\ (View Program Description)
}

California

Project Type: Market Development

Year: 2005

Grantor: Project for Public Spaces

Grantee/Cooperator: Valley Economic Development Center, Panorama City, CA

Funding: $(\$ 200,000)$

Total: $\$ 200,000$

Objective: To sponsor a business entrepreneurship training program to assist low-income vendors to start and run successful businesses in an existing Mercado created from a failed strip mall, and plan "place-making" activities for the market plaza such as screening outdoor movies, cultural festivals, and a farmers market. (OCS Funding - $\$ 250,000 \mathrm{FY}$ 05)

Project Type: Market Development

Year: 2005

Grantor: Project for Public Spaces

Grantee/Cooperator: Unity Council, Oakland

Funding: $(\$ 200,000)$

Total: $\$ 200,000$

Objective: To develop a public market and a farmers market to animate a new mixed-use development at a major transit hub and to provide access to local, fresh food to the low-income Fruitvale neighborhood. (OCS funding for FY 05 amounts to $\$ 250,000$.)

\section{Connecticut}

Project Type: Market Development

Year: 2007

Grantor: Project for Public Spaces

Grantee/Cooperator: CitySeed, Inc

Funding: $(\$ 39,200)$

Total: $\$ 39,200$

Objective: To promote New Haven's City Farmers' Markets, healthy eating and child literacy through the development of an innovative curriculum and coupon program, the Farmers Market Food Infusion Project; to encourage 3,000 New Haven children and their parents/caretakers to utilize the four CitySeed-operated markets through their involvement in literacybased programming at the Connecticut Children Museum and at New Haven School Readiness sites throughout the city. www.cityseed.org.

\section{Florida}

Project Type: Market Development

Year: 2007

Grantor: Project for Public Spaces

Grantee/Cooperator: City of High Springs/High Springs Farmers Market

Funding: $(\$ 35,500)$

Total: $\$ 35,500$

Objective: To develop plans for improving and updating the High Springs Farmers Market location to allow for a growing number of vendors and customers; to advance the market as a neighborhood gathering space; to create a community gardening project to encourage new growers and expand sustainable food sources for their community; to offset decreased state support for the Senior Farmers Market Nutrition Program and implement an EBT pilot program; and to create a three-year sustainability/business plan for the market. www.city.highsprings.com 


\section{Kentucky}

Project Type: Market Development

Year: 2005

Grantor: Project for Public Spaces

Grantee/Cooperator: Community Farm Alliance (CFA)

Funding: $(\$ 65,000)$

Total: $\$ 65,000$

Objective: For a feasibility study and location selection for a local food distribution center, farmers market store, and open-air farmers market in West Louisville (jointly owned/operated by farmers and inner city residents).

\section{Maryland}

Project Type: Market Development

Year: 2007

Grantor: Project for Public Spaces

Grantee/Cooperator: City of Takoma Park/Takoma Park Farmers Market

Strategic Partner:

Funding: $(\$ 60,000)$

Total: $\$ 60,000$

Objective: To open a satellite location of the Takoma Park Farmers Market in the busy, ethnically diverse TakomaLangley Crossroads area; to encourage the participation of minority and immigrant farmers growing or starting farms in the region, partner with CityFirst Bank, a community development financial institution (CDFI) in Washington, DC, to establish a micro-lending and technical assistance program; to implement a wireless EBT, credit/debit card processing terminal system at both market locations to facilitate food stamp use; and to reach out to WIC families.

www.takomaparkmarket.org.

\section{Michigan}

Project Type: Market Development

Year: 2005

Grantor: Project for Public Spaces

Grantee/Cooperator: Eastern Market Adv. Coalition, Detroit, MI

Funding: $(\$ 30,000)$

Total: $\$ 30,000$

Objective: Supporting an Urban Land Institute (ULI) Panel, to identify the best mix of development and job growth opportunities around Detroit's historic Eastern Market district while recommending new or expanded uses for vacant land to allow the market to become a catalyst for broader community development and revitalization.

\section{Minnesota}

Project Type: Market Development

Year: 2005

Grantor: Project for Public Spaces

Grantee/Cooperator: NDC Minneapolis, Minnesota

Funding: $(\$ 200,000)$

Total: $\$ 200,000$

Objective: Build a 60,000-square-foot indoor, multi-ethnic public market for over 60 vendors (and an open-air farmers market) in South Minneapolis as the commercial anchor tenant for the mixed-use redevelopment of a massive former Sears building now called "Midtown Exchange." The market will open in Spring 2006. (OCS Funding \$750,000 - FY 06). 
Project Type: $\underline{\text { Market Development }}$

Year: 2007

Grantor: Project for Public Spaces

Grantee/Cooperator: University of Missouri-Extension, Jasper County/Webb City Farmers Market

Funding: $(\$ 32,500)$

Total: $\$ 32,500$

Objective: To expand the market's services through the hiring of a market manager; to provide Hmong growers

marketing training and technical assistance to increase their sales; to reach out to the Latino farmer/vendor and customer communities through recruitment and the creation of Spanish language promotional materials and on-site events; to facilitate handicap accessibility, ease overcrowding, and generally improve comfort at the market; to pilot an EBT/debit pilot program to improve access to lower-income customers and provide new sources of income for farmers; and to create a three-year sustainability/business plan for the market.

\section{New Jersey}

Project Type: Market Development

Year: 2005

Grantor: Project for Public Spaces

Grantee/Cooperator: Camden Area Health Education Center

Funding: $(\$ 65,000)$

Total: $\$ 65,000$

Objective: Enhance the existing Camden Community Farmers Market at a major downtown transit center and future mixed-use development, expanding its size and provision of health and human service information and referrals.

\section{New York}

Project Type: Market Development

Year: 2005

Grantor: Project fro Public Spaces

Grantee/Cooperator: East Harlem Bus. Capital Corp

Funding: $(\$ 200,000)$

Total: $\$ 200,000$

Objective: Complete pre-development planning to revitalize an historic nine-block long public market under the viaduct of a New York City commuter rail line. (OCS Funding \$700,000 - FY 05)

\section{North Carolina}

Project Type: Market Development

Year: 2007

Grantor: Project for Public Spaces

Grantee/Cooperator: Ashe County Partnership for Children/Ashe County Farmers Market

Funding: $(\$ 29,300)$

Total: $\$ 29,300$

Objective: To work together to develop and support the operation of the newly opened Creative Food Ventures Kitchen, a shared-use commercial kitchen; to enable vendors and community members to use the kitchen's food preparation and storage facilities with the goal of increasing the number of vendors at the market; to expand the variety of value-added products offered at the market; to create business opportunities for the surrounding area; and to conduct a placemaking workshop and apply ideas generated from the community to the market shed.

\section{Ohio}


Project Type: $\underline{\text { Market Development }}$

Year: 2005

Grantor: Project for Public Spaces

Grantee/Cooperator: Appalachian Center Economic Networks

Funding: $(\$ 65,000)$

Total: $\$ 65,000$

Objective: Prepare a feasibility study to relocate the Athens Farmers Market to an indoor market centered on local products.

\section{Virginia}

Project Type: Market Development

Year: 2007

Grantor: Project for Public Spaces

Grantee/Cooperator: William Byrd Community House

Funding: $(\$ 48,800)$

Total: $\$ 48,800$

Objective: To open a new market on the grounds of and in partnership with the William Byrd Community House where they will work closely with an on-site community garden, food pantry, and youth and senior programs; to create an Urban Master Gardener program for city residents to help provide volunteers for the market and garden; and to enable a Laptop Librarian to work with the market as an 'information connector' generating ideas and to link the community house, the market, the community gardening organization and the Urban Gardener program together.

\section{Washington}

Project Type: Market Development

Year: 2005

Grantor: Project for Public Spaces

Grantee/Cooperator: Pike Place Market

Funding: $(\$ 30,000)$

Total: $\$ 30,000$

Objective: Install 11 Electronic Benefit Transfer (EBT) machines for shared use by 20 farmers, outreach to customers in 5 different languages, and enroll 16 retail tenants in the program to make fresh food more accessible to shoppers using food stamp coupons.

\section{Wisconsin}

Project Type: Market Development

Year: 2007

Grantor: Project for Public Spaces

Grantee/Cooperator: Fondy Food Center, Inc./ Fondy Farmers Market

Funding: $(\$ 44,700)$

Total: $\$ 48,800$

Objective: To reach out to Milwaukee food pantry clients through on-site cooking demonstrations at a local food pantry, as well as provide clients with cookware sets and coupons for market produce so they can prepare healthy food at home; to partner with local service agencies and a community gardening project to develop and train non-traditional market vendors in agriculture and retail marketing; and to produce a bi-weekly newsletter targeting current and potential customers featuring nutrition education, farmer and product information, shopping tips, and market activities. www.fondymarket.org.

\section{(Back to table of contents)}




\section{Individual Farmers Market Mini-Grants \\ Project for Public Spaces \\ Funding Provided by Both the Ford Foundation and the W.K. Kellogg Foundation \\ (View Program Description)}

\section{Arkansas}

Project Type: Market Development

Year: 2006

Grantor: Project for Public Spaces

Grantee/Cooperator: Fayetteville Rural Mountain Produce Exchange, Economic Opportunity Agency of Washington

County

Funding: $(\$ 10,542)$

Total: $\$ 10,542$

Objective: To accommodate the shifting demographics illustrated by the $818 \%$ increase from 1990 to 2000 among

Fayetteville residents identifying as Latino by enhancing opportunities for both Latino growers and community members to sell produce and shop at the 32 year old market.

\section{Colorado}

Project Type: Market Development

Year: 2006

Grantor: Project for Public Spaces

Grantee/Cooperator: Fairview Youth Farmers Market, Denver Urban Gardens

Funding: $(\$ 14,845)$

Total: $\$ 14,845$

Objective: To expand the community-run market and garden in a low-income, ethnically diverse neighborhood by working with Fairview Elementary School, involving more students as "Nutrition Ambassadors," and recruiting more farmers.

\section{Massachusetts}

Project Type: Market Development

Year: 2006

Grantor: Project for Public Spaces

Grantee/Cooperator: Holyoke Farmers Market, Greater Holyoke Chamber of Commerce

Funding: $(\$ 12,500)$

Total: $\$ 12,500$

Objective: To attract more Latino farmers to serve one of the largest Puerto Rican communities in the continental U.S.; provide discount coupons and van shuttles for seniors served by the Holyoke Council on Aging; and partner with the Holyoke Health Center to create incentives for their clients to increase consumption of fresh fruits and vegetables from the market.

Project Type: Market Development

Year: 2006

Grantor: Project for Public Spaces

Grantee/Cooperator: Lynn Farmers Market, The Food Project - North Shore

Funding: $(\$ 18,467)$

Total: $\$ 18,467$

Objective: To enhance the market as a key community gathering place; improve EBT/food stamp capabilities; work with local businesses, farmers, and youth growers to increase the availability of culturally appropriate produce; and position the market to relocate to a transportation hub in 2007. 


\section{Michigan}

Project Type: Market Development

Year: 2006

Grantor: Project for Public Spaces

Grantee/Cooperator: Allen Street Farmers Market, Allen Neighborhood Center

Funding: $(\$ 19,940)$

Total: $\$ 19,940$

Objective: To partner with a new youth-run greenhouse in a downtown park to expand the market's product mix and growing season. Attract more customers by improving EBT/food stamp capability and promoting the market throughout the neighborhood.

\section{Minnesota}

Project Type: Market Development

Year: 2006

Grantor: Project for Public Spaces

Grantee/Cooperator: Minneapolis Midtown Public Market, Corcoran Neighborhood Organization

Funding: $(\$ 25,000)$

Total: $\$ 25,000$

Objective: To expand the existing market with more immigrant, minority, and youth vendors, working with such programs as the Minnesota Food Association's "New Immigrant Agriculture Project." Open an additional market at Midtown Global Market, a new year-round market, and establish an EBT pilot program at both markets.

\section{New York}

Project Type: Market Development

Year: 2007

Grantor: Project for Public Spaces

Grantee/Cooperator: United Community Centers, Inc./East New York Farms!

Funding: $(\$ 48,742)$

Total: $\$ 48,742$

Objective: To move the location of the East New York Farmers Market to a closed street in front of their half-acre urban farm for increased visibility, convenience, and greater potential for placemaking activities; to double the size of their urban farm to one acre to help increase their market's supply of fresh, locally grown produce; to better serve their customers who use FMNP coupons, the market will hire certified nutrition educators to conduct cooking demonstrations in local WIC centers and organize focus groups with FMNP recipients to discuss how to lower existing barriers to coupon redemption.

Ohio

Project Type: Market Development

Year: 2006

Grantor: Project for Public Spaces

Grantee/Cooperator: Cincinnati Findlay Farmers Market

Funding: $(\$ 24,690)$

Total: $\$ 24,690$

Objective: To implement a system to allow shoppers from Ohio, Indiana, and Kentucky, which adjoin the 153 year-old, six-day-a-week market to use EBT/food stamps to purchase fresh, health food and to improve direct marketing opportunities for farmers.

Project Type: $\underline{\text { Market Development }}$ 
Year: 2007

Grantor: Project for Public Spaces

Grantee/Cooperator: Appalachian Center for Economic Networks (ACEnet)/Athens Farmers Market

Funding: $\$ 38,000$

Total: $\$ 38,000$

Objective: To create new marketing programs to attract low-income customers and increase sales for farmers and other vendors; to supplement current vendor training through new classes on the new EBT system and marketing programs, as well as best practices for financial systems and customer service with EBT, WIC and Senior FMNP; and to create a threeyear sustainability/business plan. www.athensfarmersmarket.org

Project Type: Market Development

Year: 2007

Grantor: Project for Public Spaces

Grantee/Cooperator: Lucas County Improvement Corporation/Toledo Farmers Market

Funding: $(\$ 41,000)$

Total: $\$ 41,000$

Objective: To develop and host food and health activities, such as cooking demonstrations and community events, at the Toledo Farmers Market; to provide more outreach to low-income customers to better support their year-old EBT program; to work with University of Toledo's Urban Affairs Center as a strategic partner to help broaden the market's influence in the Toledo area; and to create a three-year sustainability/business plan. www.toledofarmersmarket.org

\section{Oregon}

Project Type: Market Development

Year: 2006

Grantor: Project for Public Spaces

Grantee/Cooperator: Hacienda Community Development Corporation

Funding: $(\$ 10,000)$

Total: $\$ 10,000$

Objective: To develop a training and support system for Latino market vendors and facilitate their placement at farmers markets throughout the city of Portland; develop the capacity of vendors to access additional markets on their own; and create a model program which vendors and markets in other cities could use.

\section{Virginia}

Project Type: Market Development

Year: 2006

Grantor: Project for Public Spaces

Grantee/Cooperator: Lynchburg Community Market, City of Lynchburg Parks and Recreation

Funding: $(\$ 12,700)$

Total: $\$ 12,700$

Objective: To partner with Lynchburg Grows, an organization providing workforce training for disadvantaged individuals, to grow produce in its 6.5 acre urban greenhouse and on 5 community garden sites, and to create jobs selling produce on a year-round basis at the historic market hall, founded in 1783.

\section{Washington}

Project Type: Market Development

Year: 2006

Grantor: Project for Public Spaces

Grantee/Cooperator: Mount Vernon Farmers Market, Friends of Skagit County

Funding: $(\$ 20,333)$

Total: $\$ 20,333$

Objective: To increase availability of fresh food for school children and their families, implement EBT, open an additional market at a local hospital, sponsor kids' activities with the children's museum, and build visibility of the market as an integral part of the downtown's redevelopment plan.

Project Type: $\underline{\text { Market Development }}$ 
Year: 2006

Grantor: Project for Public Spaces

Grantee/Cooperator: Prosser Farmers Market Cooperative

Funding: $(\$ 12,015)$

Total: $\$ 12,015$

Objective: To attract a more diverse customer base in a small town of 5,000 residents; enhance the market as an outlet for the area's increasing number of small, minority, and new farmers; and expand outreach to schools and local food cooperatives.

\section{Wisconsin}

Project Type: Market Development

Year: 2006

Grantor: Project for Public Spaces

Grantee/Cooperator: South Madison Community Farmers Market

Funding: $(\$ 21,246)$

Total: $\$ 21,246$

Objective: To add a third market day at The Villager, a strip mall being redeveloped as a community center with a library, health center, and technical college; expand a youth gardening program to grow produce and operate a stall at the market; and develop market-centered Community Supported Agriculture programs.

\section{(Back to table of contents)}




\title{
Private Sector and Foundation Farmers Market Projects
}

\author{
Market Network Grants \\ Project for Public Spaces \\ Funding Provided by the W.K. Kellogg Foundation \\ (View Program Description)
}

\section{California}

Project Type: Market Development

Year: 2006

Grantor: Project for Public Spaces

Grantee/Cooperator: Southland Farmers Market Association

Funding: $(\$ 100,000)$

Total: $\$ 100,000$

Objective: To develop eight farmers markets at public schools throughout Los Angeles, increase access to affordable food, enhance the role of schools as community places, and create a model for developing markets at schools for school districts and farmers markets around the county.

\section{Kentucky}

Project Type: Market Development

Year: 2006

Grantor: Project for Public Spaces

Grantee/Cooperator: Community Farm Alliance

Funding: $(\$ 100,000)$

Total: $\$ 100,000$

Objective: The network will complete a community food assessment and provide economic opportunities for local residents and Kentucky farmers by expanding existing farmers markets as well as by developing a local food distribution center and a shared-use commercial kitchen to foster regional entrepreneurship.

\section{Ontario, Canada}

Project Type: Market Development

Year: 2006

Grantor: Project for Public Spaces

Grantee/Cooperator: FoodShare Toronto

Funding: $(\$ 100,000)$

Total: $\$ 100,000$

Objective: Work with community organizations to develop at least three new markets in low-income Toronto communities that improve access to fresh food and create community gathering places; partner with community development groups and health and other social service agencies to develop a model collaborative approach for creating and sustaining farmers markets in low-income neighborhoods.

\section{Louisiana}

Project Type: Market Development

Year: 2005

Grantor: Project for Public Spaces

Grantee/Cooperator: marketumbrella.org/Loyola University

Funding: $(\$ 100,000)$

Total: $\$ 100,000$

Objective: To help resume operations of public markets and farmers markets in the region, in ways especially designed to meet post-Katrina needs, with the potential to engage new partners. The Ford Foundation provided an additional $\$ 150,000$ in funding from its Katrina relief efforts, for a total commitment of $\$ 250,000$. 
New Jersey

Project Type: Market Development

Year: 2006

Grantor: Project for Public Spaces

Grantee/Cooperator: Camden Area Health Education Center (AHEC)

Funding: $(\$ 60,000)$

Total: $\$ 60,000$

Objective: To expand a downtown community farmers market, strengthen a neighborhood market, and start a new farmers market, while increasing the markets' impacts on health and wellness by improving access to nutritious food, providing preventative healthcare services, and establishing safe community gathering places.

\section{New York}

Project Type: Market Development

Year: 2006

Grantor: Project for Public Spaces

Grantee/Cooperator: Just Food

Funding: $(\$ 55,000)$

Total: $\$ 55,000$

Objective: To bring together four existing operators of markets in low-income neighborhoods in Brooklyn, NY with nonprofit and local government partners to identify community opportunities, organize a borough-wide stakeholders meeting, and write a strategic plan to create a sustainable network involving new partners.

\section{Washington}

Project Type: Market Development

Year: 2006

Grantor: Project for Public Spaces

Grantee/Cooperator: Wenatchee Valley Farmers Market Association

Funding: $(\$ 60,000)$

Total: $\$ 60,000$

Objective: Hire a project coordinator to do outreach and management, develop a permanent regional farmers market, boost opportunities for both farmers and consumers, and expand existing markets while doing outreach to the Latino community and supporting programs on nutrition education and healthy living.

\section{(Back to table of contents)}




\title{
Private Sector and Foundation Farmers Market Projects
}

\author{
State/Regional Market Association Grants \\ Project for Public Spaces \\ Funding Provided by the W.K. Kellogg Foundation \\ (View Program Description)
}

Michigan

Project Type: Producer Training and Support

Year: 2006

Grantor: Project for Public Spaces

Grantee/Cooperator: Michigan Food and Farming Systems (MIFFS)

Funding: $(\$ 87,000)$

Total: $\$ 87,000$

Objective: To create a new Michigan Farmers Market Association that facilitates communication between markets, improves marketing, documents economic benefits, helps markets diversify their customer bases, and collaborates with state and local agencies to impact policies for farmers markets.

\section{New Mexico}

Project Type: Producer Training and Support

Year: 2006

Grantor: Project for Public Spaces

Grantee/Cooperator: Farm to Table

Funding: $(\$ 86,000)$

Total: $\$ 86,000$

Objective: To work with the New Mexico Tribal Extension Task Force to develop the New Mexico Native American Farmers' Market Association, culturally appropriate models for farmers markets that best serve and support the communities they are in, and assist in the implementation of at least four new farmers markets.

\section{New York}

Project Type: Producer Training and Support

Year: 2006

Grantor: Project for Public Spaces

Grantee/Cooperator: Farmers' Market Federation of New York

Funding: $(\$ 79,000)$

Total: $\$ 79,000$

Objective: To organize a statewide conference, "Farmers' Markets and Community Development" and redesign and update the Federation website to increase awareness of the value of farmers markets amongst New York State politicians and community leaders and to develop lasting partnerships that strengthen support for farmers' markets.

\section{$\underline{\text { South Carolina }}$}

Project Type: Producer Training and Support

Year: 2006

Grantor: Project for Public Spaces

Grantee/Cooperator: South Carolina Department of Agriculture

Funding: $(\$ 78,000)$

Total: $\$ 78,000$

Objective: To collaborate with community and faith-based organizations and governmental agencies to develop a strategic plan focused on markets and improved access to food as tools for reducing obesity and improving the quality of life for low-income families in South Carolina. Help small farmers acquire skills to sell at farmers markets, offer opportunities for group purchases of supplies and insurance, and develop up to ten new farmers markets with EBT/Food Stamp capacity.

\section{(Back to table of contents)}

